\title{
Testosterone protects from metabolic syndrome-associated prostate inflammation: an experimental study in rabbit
}

\author{
Linda Vignozzi ${ }^{1}$, Annamaria Morelli ${ }^{1}$, Erica Sarchielli ${ }^{3}$, Paolo Comeglio ${ }^{1}$, Sandra Filippi ${ }^{4}$, Ilaria Cellai ${ }^{1}$, \\ Elena Maneschi ${ }^{1}$, Sergio Serni ${ }^{5}$, Mauro Gacci ${ }^{5}$, Marco Carini ${ }^{5}$, Marie-Pierre Piccinni ${ }^{6}$, Farid Saad ${ }^{7,8}$, \\ Luciano Adorini ${ }^{9}$, Gabriella B Vannelli ${ }^{3}$ and Mario Maggi ${ }^{1,2}$
}

\footnotetext{
${ }^{1}$ Sexual Medicine and Andrology Unit, Department of Clinical Physiopathology, University of Florence, Viale Pieraccini 6, Florence 50139, Italy

${ }^{2}$ CIRMAR (Centro Interuniversitario di Ricerca sulle basi molecolari della Malattie della Riproduzione), Milan, Italy

${ }^{3}$ Department of Anatomy, Histology and Forensic Medicine, ${ }^{4}$ Interdepartmental Laboratory of Functional and Cellular Pharmacology of Reproduction,

${ }^{5}$ Department of Urology and ${ }^{6}$ Immunoallergology Unit, Department of Internal Medicine, Center of Excellence for Research, Transfer and High Education DENOTHE, University of Florence, Florence, Italy

${ }^{7}$ Scientific Affairs Men's Healthcare, Bayer Pharma AG, Berlin, Germany

${ }^{8}$ Gulf Medical University, Ajman, United Arab Emirates

${ }^{9}$ Intercept Pharmaceuticals Italia Srl, Via Togliatti, 06073 Corciano, Perugia, Italy

(Correspondence should be addressed to M Maggi at Sexual Medicine and Andrology Unit, Department of Clinical Physiopathology, University of Florence; Email: m.maggi@dfc.unifi.it)
}

\begin{abstract}
Metabolic syndrome (MetS) and benign prostatic hyperplasia $(\mathrm{BPH}) /$ lower urinary tract symptoms (LUTS) are often associated. One of their common denominators is hypogonadism. However, testosterone supplementation is limited by concerns for potential prostatic side effects. The objective was to determine whether MetS-associated prostate alterations are prevented by testosterone supplementation. We used a previously described animal model of MetS, obtained by feeding male rabbits a high-fat diet (HFD) for 12 weeks. Subsets of HFD rabbits were treated with testosterone or with the farnesoid X receptor agonist INT-747. Rabbits fed a standard diet were used as controls. HFD-animals develop hypogonadism and all the MetS features: hyperglycemia, glucose intolerance, dyslipidemia, hypertension, and visceral obesity. In addition, HFD-animals show a prostate inflammation. Immunohistochemical analysis demonstrated that HFD-induced prostate fibrosis, hypoxia, and inflammation.
\end{abstract}

The mRNA expression of several proinflammatory (IL8, IL6, IL1 $\beta$, and TNF $\alpha$ ), T lymphocyte (CD4, CD8, Tbet, Gata3, and ROR $\gamma \mathrm{t}$ ), macrophage (TLR2, TLR4, and STAMP2), neutrophil (lactoferrin), inflammation (COX2 and RAGE), and fibrosis/myofibroblast activation (TGF $\beta, \mathrm{SM} 22 \alpha, \alpha \mathrm{SMA}$, RhoA, and ROCK1/ROCK2) markers was significantly increased in HFD prostate. Testosterone, as well as INT-747, treatment prevented some MetS features, although only testosterone normalized all the HFD-induced prostate alterations. Interestingly, the ratio between testosterone and estradiol plasma level retains a significant, negative, association with all the fibrosis and the majority of inflammatory markers analyzed. These data highlight that testosterone protects rabbit prostate from MetS-induced prostatic hypoxia, fibrosis, and inflammation, which can play a role toward the development/progression of BPH/LUTS.

Journal of Endocrinology (2012) 212, 71-84

\section{Introduction}

Lower urinary tract symptoms (LUTS), generally regarded as a hallmark of benign prostatic hyperplasia (BPH), result from static (prostate enlargement), dynamic ( $\boldsymbol{\alpha}$-receptor-mediated muscle tension), and inflammatory (prostate inflammation) components (Nickel 1994, Fibbi et al. 2010, Moul \& McVary 2010, Donnell 2011).

A growing body of evidence has documented a strong and independent association between BPH/LUTS and obesity/ metabolic syndrome (MetS; Mongiu \& McVary 2009, Moul \& McVary 2010, Gorbachinsky et al. 2010, Parsons 2011).
In epidemiological studies, LUTS was associated with several MetS features, including obesity (Rohrmann et al. 2004, Seim et al. 2005, Laven et al. 2008), hypertension and type 2 diabetes mellitus (Michel et al. 2000, 2004, Tomita et al. 2009), hyperglycemia and low high density lipoprotein (HDL) cholesterol (Martin et al. 2011), and high polyunsaturated fat energy intake (Litman et al. 2007). Interestingly, we have recently demonstrated a positive association between obesity and ultrasound or biochemical (seminal interleukin 8 (IL8)) features of prostate inflammation (Lotti et al. 2011).

Relationship between MetS and LUTS has been investigated in some animal models (Andersson et al. 2011), 
including a mouse model of type 2 diabetes mellitus/obesity (diabesity) in which prostate inflammation and bladder dysfunction were evident (Krajewska et al. 2008). MetS appears, therefore, related to the development of LUTS. Potential common etiological factors include hyperglycemia, insulin resistance, low-grade chronic inflammation (Moul \& McVary 2010), and also hypogonadism (Pradidarcheep 2008). Recent data have in fact suggested that low testosterone in males might be considered an additional MetS component (Corona et al. 2009, Zitzmann 2009, Corona et al. 2011a,b, Traish et al. 2011). Although testosterone supplementation in MetS significantly improves metabolic parameters (fasting glucose, glucose tolerance, waist circumference, triglycerides, and HDL cholesterol; Corona et al. 2011a), concerns of potential prostatic side effects strongly limit a widespread clinical use. These concerns are based on the concept that androgens are essential for prostate growth, which potentially can worsen LUTS. However, some prospective (Kristal et al. 2008, Trifiro et al. 2010) and cross-sectional studies (Schatzl et al. 2000, Tan et al. 2003, Roberts et al. 2004, Miwa et al. 2008, St Sauver et al. 2011) have demonstrated an inverse association between serum testosterone and LUTS or BPH. Consistent with these observations, testosterone replacement therapy has been reported to relieve LUTS in hypogonadal men with both BPH (Holmäng et al. 1993, Saad et al. 2007, Kalinchenko et al. 2008, Karazindiyanoğlu \& Çayan 2008, Saad et al. 2008, Amano et al. 2010, Shigehara et al. 2011) and MetS (Haider et al. 2009).

In this study, we use a previously described animal model of high-fat diet (HFD)-induced MetS in rabbit. MetS was characterized by hyperglycemia, glucose intolerance, hypercholesterolemia, hypertrygliceridemia, hypertension, increased visceral fat mass, and hypogonadotropic hypogonadism (Filippi et al. 2009, Vignozzi et al. 2011), We now report an additional feature of HFD-induced MetS: prostate inflammation. We also investigate the effect of dosing testosterone or INT-747, a farnesoid X receptor (FXR) agonist, because we previously demonstrated that these treatments could ameliorate/treat several MetS features (Filippi et al. 2009, Vignozzi et al. 2011). FXR is steroid nuclear receptor critically involved in the regulation of the hepato-biliary system, which also regulates lipid and glucose homeostasis, even in the HFD-induced MetS (Morelli et al. 2011). In previous studies, while testosterone supplementation also reverted MetS-associated hypogonadism (Filippi et al. 2009), INT-747 did not (Vignozzi et al. 2011).

\section{Materials and Methods}

\section{HFD rabbit model}

HFD-induced MetS rabbit model, as well as testosterone or INT-747 treatments, has been performed as described previously (Filippi et al. 2009, Vignozzi et al. 2011). Briefly, male New Zealand White rabbits (Charles River, Calco,
Table 1 Primer sequences for quantitative RT-PCR in rabbit samples
Gene names

$T L R 2$

TLR4

CD4

CD8

LACT

STAMP2

RAGE

COX2

IL8

$I L 1 \beta$

$T N F \alpha$

IL6

TGF $\beta 1$

RhoA

$\alpha S M A$

$S M 22 \alpha$

ROCK1

ROCK2

AR

$E R \alpha$

$E R \beta$

GPR30/GPER1

FXR

ROR $\gamma t$

GATA3

Tbet

\section{Primer sequences}

F: 5'-CCGCGGGTTCCCCAGGTTG-3'

R: 5'-GGATCTGGAGCGCCCATCGC-3'

F: $5^{\prime}$-GCGGGTGGAGCTGTATCGCC-3'

R: 5'-CTTGGGTTCAGCCGGGCAGG-3' F: 5'-CAGGTCAAGATCCTGGGAAA-3' R: 5'-CCCCCACTTCGCAGATATAA-3' F: 5'-AGGGACTACACTTGGCATGG- $3^{\prime}$ R: 5'-TGCAGAAGTAGACGCCAGTG-3' F: 5'-CCCTGACATCACCTGGAACT-3' R: 5'-TCACCCCTCTCGTTACCAAC-3' F: $5^{\prime}$-CGATGGAGGTCAAGGAACAT- $3^{\prime}$ R: 5'-CCAGTTTGGACTGGACGAAT-3' F: 5'-GCAGTCAGAGCTGATGGTGA-3' R: 5'-GCTACTGCTCCACCTTCTGG-3' F: $5^{\prime}$-AGTGTGCGATGTGCTCAAAC- $3^{\prime}$ R: 5'-AAAAGCAGCTCTGGGTCAAA-3' F: 5'-CTCTCTTGGCAACCTTCCTG-3' R: 5'-TTGCACAGTGAGGTCCACTC-3' F: $5^{\prime}$-CCACAGTGGCAATGAAAATG- $3^{\prime}$ R: 5'-AGAAAGTTCTCAGGCCGTCA-3' F: 5'-GTCTTCCTCTCTCACGCACC-3' R: 5'-TGGGCTAGAGGCTTGTCACT-3' F: 5'-GAACAGAAAGGAGGCACTGG-3' R: 5'-CTCCTGAACTTGGCCTGAAG-3' F: 5'-CTTCCGCAAGGACCTGGG-3' R: 5'-CGGGTTGTGCTGGTTGTAC-3' F: 5'-CCCTCCTCATCGTCTTCAGT-3' R: 5'-GTCGATGGAGAAGCACATGA-3' F: 5'-ACTGGGACGACATGGAAAAG- $3^{\prime}$ R: 5'-TACATGGCTGGGACATTGAA- $3^{\prime}$ F: $5^{\prime}$-CAAGACCGACATGTTCCAGA-3' R: 5'-CTATGTTGCTGCCCATCTGA-3' F: $5^{\prime}$-CGGAAGTGAACTCGGATTGT- $3^{\prime}$ R: 5'-TCCAAATGCACCTCTACCAA-3' F: $5^{\prime}$-CTACGGACGGGAATGTGACT- $3^{\prime}$ R: 5'-TGTTAAGAAGGCGCAGATGA-3' F: $5^{\prime}$-CCGTAACTTGCATGTGGATG-3' R: 5'-GCTGTACATCCGGGACTTGT-3' F: 5'-GCGTTCTACAGGCCAAGTTC-3' R: 5'-TCAATTGTGCACTGGTTGGT- $3^{\prime}$ F: 5'-TAGTGCGGAGACGGAGAAGT-3' R: 5'-GGACAGCATCATGGAGGTCT-3' F: 5'-TGCTCGTCTTCTTCATCTGC-3' R: 5'-CGTCTTCTGCTCCACGTACA-3' F: 5'-CCCCAAGTTCAACCACAGAT-3' R: 5'-CCAGATGCTCTGTCTCCACA-3' F: 5'-GGGCTTCATACCACCTTGAA-3' R: 5'-GTGCTCTGGGCCTATCTCTG-3' F: 5'-AGGCAGGGAGTGTGTGAACT-3' R: 5'-CGTCGTGGTCTGACAGTTTG-3' F: 5'-CCTTCCAAGAGACGCAGTTC-3' R: 5'-AGGAAGCTCGGGGTAGAAAC-3'
TLR2, toll-like receptor 2; CD4, T-cell surface glycoprotein cluster of differentiation 4; LACT, lactoferrin; STAMP2, six transmembrane protein of prostate 2; RAGE, receptor for advanced glycation endproducts; COX2, cyclooxygenase isoenzyme 2; IL8, interleukin 8 ; TNF $\alpha$, tumor necrosis factor $\alpha$; TGF $\beta 1$, transforming growth factor $\beta$; RhoA, Ras homolog gene family, member $\mathrm{A} ; \alpha \mathrm{SMA}, \alpha$-smooth muscle actin; SM22 $\alpha$, transgelin; ROCK1, Rhoassociated coiled coil-containing kinase type 1; AR, androgen receptor; $E R \alpha$, estrogen receptor $\alpha$; GPR30/GPER1, G protein-coupled receptor 30/G protein-coupled estrogen receptor 1 ; FXR, farnesoid $X$ receptor; ROR $\gamma t$, retinoic acid receptor-related orphan receptor $\gamma t$; GATA3, GATA-binding protein 3; Tbet, T-box transcription factor 3.

www.endocrinology-journals.org 
Lecco, Italy), weighing about $3 \mathrm{~kg}$ (mean age 15 weeks), were individually caged under standard conditions in a temperature and humidity controlled room on a $12 \mathrm{~h}$ light: $12 \mathrm{~h}$ darkness cycle. Water and food were unrestricted throughout the study. After 1 week of standard rabbit diet, animals were randomly numbered and assigned to different groups: control $(n=22)$ or treatment group $(n=44)$. The control group continued to receive a standard diet (Harlan-Global Diet 2030, produced by Mucedola s.r.l, Milan, Italy, constituted by water $12 \%$, protein $16 \cdot 5 \%$, fiber $15 \cdot 5 \%$, vegetable fat $3 \cdot 5 \%$, and carbohydrate $44 \%$ ), while the treatment group was fed a HFD (enriched by $0.5 \%$ animal-derived cholesterol and $4 \%$ peanut oil, Mucedola s.r.l), for 12 weeks (HFD rabbits). A first subset of HFD rabbits $(n=13)$ was supplemented with a pharmacological dose of testosterone $(30 \mathrm{mg} / \mathrm{kg}$ weekly i.m. for 12 weeks). A second subset of HFD rabbits $(n=14)$ was treated with a FXR agonist, INT-747 $(10 \mathrm{mg} / \mathrm{kg}$ body weight (bw), daily for 5 days a week for 12 weeks, by oral gavage). Any treatment (including diets and/or drug administration) was performed by a dedicated technician. Blood samples for glucose, total cholesterol, triglycerides, testosterone, $17 \beta$-estradiol $\left(\mathrm{E}_{2}\right)$, and leptin analyses were obtained via marginal ear vein at time 0 (baseline) and at week 12 in all groups. The blood was immediately centrifuged at $1000 \mathrm{~g}$ for $20 \mathrm{~min}$, and collected plasma was stored at $-20{ }^{\circ} \mathrm{C}$ until assayed. Mean arterial blood pressure was measured by a polyethylene catheter inserted into a femoral artery at week 12 , after pentobarbital $(45 \mathrm{mg} / \mathrm{kg})$ sedation as described previously (Filippi et al. 2009, Vignozzi et al. 2011). Shortly afterwards, the rabbits were killed by a lethal dose of pentobarbital. Leukocyte esterase and nitrites have been detected in rabbit urine by semi-quantitative urinary dipsticks (Combur-Test, Roche Diagnostics).

\section{Collection of rabbit prostate}

Rabbit prostate, seminal vesicles, testis, and visceral fat were obtained and harvested from the different experimental groups and appropriately stored for the subsequent analyses (Filippi et al. 2009, Vignozzi et al. 2011). In particular, immediately after removal, tissue samples were shock frozen in liquid nitrogen and stored at $-80{ }^{\circ} \mathrm{C}$ until RNA preparation. For immunohistochemistry preparations, tissues were immediately fixed in Bouin's solution and embedded in paraffin. All the animal experiments were performed in accordance to D.L. 116/92 and approved by the Institutional Animal Care and Use Committee of the University of Florence.

Measurement of cholesterol, triglycerides, glycemia, testosterone, $E_{2}$, and leptin in rabbits

Blood samples were obtained via marginal ear vein at time 0 (baseline) and at week 12 in all groups. Plasma cholesterol, triglycerides, glucose, and testosterone levels were measured after appropriate extraction when needed, as described

Table 2 Metabolic and hormonal parameters in the rabbit model of metabolic syndrome. Results are reported as mean \pm S.E.M.

\begin{tabular}{|c|c|c|c|c|}
\hline & $\begin{array}{c}\text { Control } \\
(n=22)\end{array}$ & $\begin{array}{l}\text { HFD } \\
(n=17)\end{array}$ & $\begin{array}{c}\text { HFD }+ \\
\text { testosterone } \\
\quad(n=13)\end{array}$ & $\begin{array}{l}\text { HFD + INT-747 } \\
\quad(n=14)\end{array}$ \\
\hline \multicolumn{5}{|l|}{ Total body weight (g) } \\
\hline Baseline & $3219 \cdot 70 \pm 51 \cdot 84$ & $3250 \cdot 93 \pm 54 \cdot 65$ & $3260 \cdot 48 \pm 53 \cdot 81$ & $3378 \cdot 61 \pm 52 \cdot 10$ \\
\hline Week 12 & $3763 \cdot 00 \pm 38 \cdot 27$ & $3678 \cdot 80 \pm 43 \cdot 69$ & $3807 \cdot 00 \pm 60 \cdot 36$ & $3614.94 \pm 76.93$ \\
\hline \multicolumn{5}{|l|}{ Blood glucose $(\mathrm{g} / \mathrm{l})$} \\
\hline Baseline & $1 \cdot 31 \pm 0 \cdot 03$ & $1 \cdot 32 \pm 0 \cdot 03$ & $1 \cdot 17 \pm 0 \cdot 04$ & $1 \cdot 25 \pm 0 \cdot 06$ \\
\hline Week 12 & $1 \cdot 43 \pm 0 \cdot 04$ & $1 \cdot 96 \pm 0 \cdot 08^{\ddagger \text { ฯ }}$ & $1 \cdot 61 \pm 0 \cdot 07^{\ddagger, a}$ & $1 \cdot 41 \pm 0 \cdot 07^{b}$ \\
\hline \multicolumn{5}{|l|}{ Cholesterol (mg/dl) } \\
\hline Baseline & $38 \cdot 14 \pm 2 \cdot 62$ & $45 \cdot 89 \pm 2 \cdot 36$ & $45 \cdot 35 \pm 2 \cdot 39$ & $36 \cdot 78 \pm 1 \cdot 96$ \\
\hline Week 12 & $44 \cdot 95 \pm 3 \cdot 74$ & $1331 \cdot 85 \pm 59 \cdot 27^{ \pm, \uparrow}$ & $1251 \cdot 70 \pm 49 \cdot 37^{\neq, 9}$ & $1242 \cdot 06 \pm 91 \cdot 47^{ \pm \text {, }}$ \\
\hline \multicolumn{5}{|l|}{ Triglycerides (mg/dl) } \\
\hline Baseline & $86 \cdot 43 \pm 4 \cdot 95$ & $88 \cdot 90 \pm 4 \cdot 39$ & $94 \cdot 62 \pm 7 \cdot 32$ & $76 \cdot 83 \pm 5 \cdot 67$ \\
\hline Week 12 & $114 \cdot 20 \pm 7 \cdot 41$ & $302 \cdot 01 \pm 31 \cdot 24^{ \pm, \pi}$ & $322 \cdot 64 \pm 27 \cdot 45^{ \pm, \oplus}$ & $231 \cdot 22 \pm 36 \cdot 75^{+, \|}$ \\
\hline \multicolumn{5}{|l|}{ Testosterone (nmol/l) } \\
\hline Baseline & $7 \cdot 00 \pm 1 \cdot 66$ & $9 \cdot 12 \pm 2 \cdot 07$ & $4 \cdot 17 \pm 0 \cdot 66$ & $9 \cdot 83 \pm 3 \cdot 36$ \\
\hline Week 12 & $6 \cdot 34 \pm 0 \cdot 84$ & $1 \cdot 58 \pm 0 \cdot 32^{\neq, \uparrow}$ & $15 \cdot 38 \pm 2 \cdot 86^{\neq, \pi, c}$ & $1 \cdot 19 \pm 0 \cdot 33^{t, \pi}$ \\
\hline OGTT (AUC; week 12) & $168 \cdot 91 \pm 6 \cdot 05$ & $233 \cdot 48 \pm 8 \cdot 99$ & $191 \cdot 50 \pm 6 \cdot 24^{\mathrm{b}}$ & $194 \cdot 32 \pm 9 \cdot 75^{\mathrm{a}}$ \\
\hline MAP (mmHg; week 12) & $96 \cdot 12 \pm 2 \cdot 71$ & $135 \cdot 46 \pm 3 \cdot 72^{9}$ & $111 \cdot 30 \pm 1 \cdot 80^{\dagger, \mathrm{c}}$ & $129 \cdot 16 \pm 4 \cdot 35^{\pi}$ \\
\hline Seminal vesicles weight (mg; week 12) & $803 \cdot 24 \pm 38 \cdot 61$ & $496 \cdot 76 \pm 29 \cdot 68$ & $1375 \cdot 24 \pm 98 \cdot 35^{\ddagger, c}$ & $595 \cdot 00 \pm 57 \cdot 01$ \\
\hline Testis weight (g; week 12) & $3 \cdot 67 \pm 0 \cdot 06$ & $2 \cdot 99 \pm 0 \cdot 07^{\top}$ & $1 \cdot 65 \pm 0 \cdot 06^{\pi, c}$ & $2 \cdot 41 \pm 0 \cdot 13^{\mp, b}$ \\
\hline Prostate weight ( $\mathrm{g}$; week 12) & $0.57 \pm 0.07$ & $0 \cdot 25 \pm 0 \cdot 02^{\S}$ & $0 \cdot 93 \pm 0 \cdot 06^{\|, c}$ & $0 \cdot 28 \pm 0 \cdot 04^{\mathrm{a}}$ \\
\hline $\begin{array}{l}\text { Visceral adipose tissue weight (g; week } 12 \text {; } \\
\text { Percentage of total body weight, } \% \text { ) }\end{array}$ & $\begin{array}{l}34 \cdot 58 \pm 1 \cdot 83 \\
(0 \cdot 84 \pm 0 \cdot 04)\end{array}$ & $\begin{array}{l}41 \cdot 94 \pm 1 \cdot 72^{\S} \\
(1 \cdot 12 \pm 0 \cdot 04)^{\Uparrow}\end{array}$ & $\begin{array}{l}4 \cdot 19 \pm 0 \cdot 78^{\varpi, c} \\
(0 \cdot 10 \pm 0 \cdot 02)^{\pi, c}\end{array}$ & $\begin{array}{l}15 \cdot 23 \pm 2 \cdot 05^{\uparrow, c} \\
(0 \cdot 41 \pm 0 \cdot 05)^{\pi, c}\end{array}$ \\
\hline
\end{tabular}

AUC, incremental area under the curve of glucose blood level during oral glucose tolerance test (OGTT); MAP, mean arterial pressure. ${ }^{+} P<0 \cdot 01$, and ${ }^{\ddagger} P<0 \cdot 001$ vs baseline. ${ }^{\S} P<0 \cdot 05, " \| P<0 \cdot 01$, and ${ }^{\top} P<0 \cdot 001$ vs control week $12 .{ }^{\mathrm{a}} P<0 \cdot 05,{ }^{\mathrm{b}} P<0 \cdot 01$, and ${ }^{\mathrm{C}} P<0 \cdot 001$ vs HFD week 12 . 

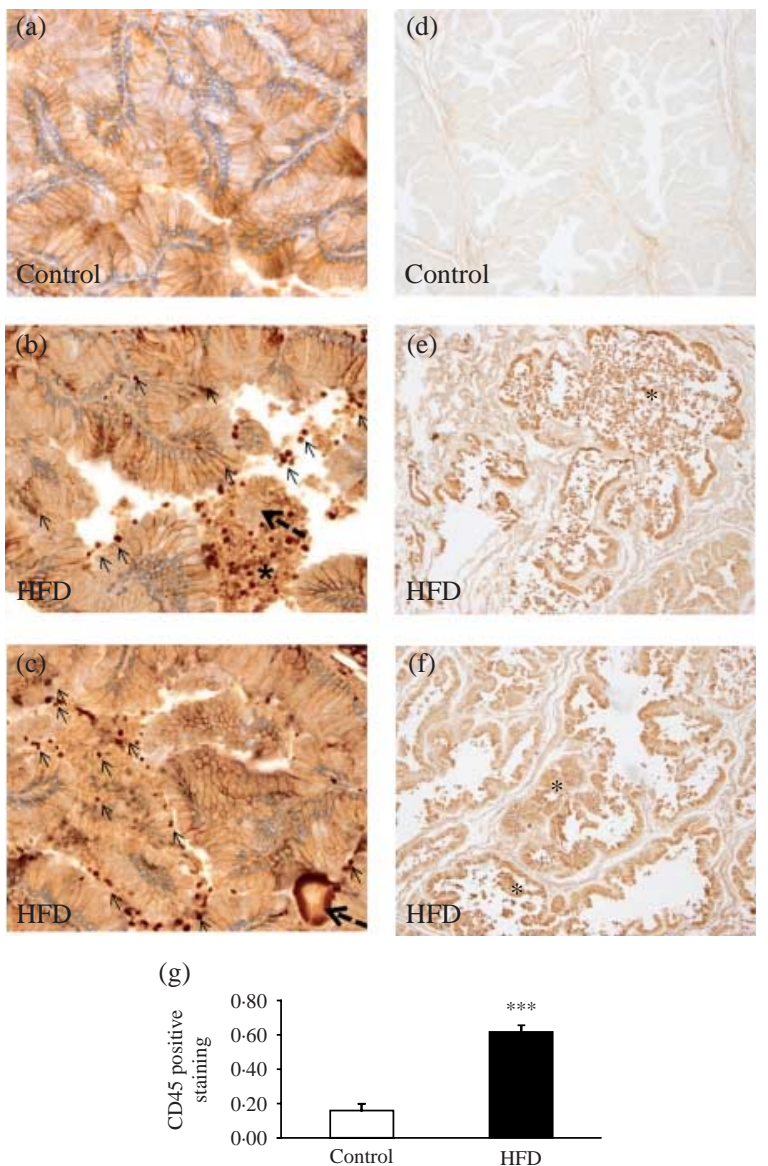

Figure 1 Infiltrating inflammatory CD45-positive cells in prostate sections. Prostate sections stained with CD45 of control (a and d), HFD (b and c, e and f). Upper panels: magnification $20 \times$ of sections counterstained with hematoxylin and eosin; lower panels magnification $4 \times$ of sections not counterstained with hematoxylin and eosin. A normal prostate gland composed by a luminal epithelium and a thick glandular-adjacent stroma with rare infiltrating CD45-positive inflammatory cells was present in control ( $a$ and d). In prostate sections of HFD ( $b$ and $c$, e and f) CD45-round positive cells were extensively present in both interductal stroma and intertwined within the epithelial glands (solid arrow).

Numerous CD45-round positive cells were also present within the glandular lumen $(*)$ often associated with corpora amylacea (dashed arrow; b and c) in HFD. Images are representative of three independent experiments. (g) Computer-assisted quantitative image analysis of immunpositive staining after background subtraction in three independent experiments ( $n=3$ for each group). ${ }^{* * *} P<0 \cdot 001$ vs control.

previously (Filippi et al. 2009, Vignozzi et al. 2011). Briefly, plasma cholesterol, triglycerides, and glucose levels were measured by an Automated System (ADVIA 2004 Siemens Chemistry System; Siemens Science Medical Solution Diagnostic, Tarrytown, NY, USA). Plasma testosterone and $\mathrm{E}_{2}$ levels were measured by an automated chemiluminescence system (Immulite 2000 Siemens, Siemens Healthcare Diagnostics, Deerfield, IL, USA), after appropriate extraction.
For extraction, samples were mixed with four volumes of diethyl ether for $15 \mathrm{~min}$, centrifuged for $5 \mathrm{~min}$ at $400 \mathrm{~g}$, and the aqueous phase frozen in dry ice. The organic phase was recovered, evaporated to dryness under a nitrogen stream, and reconstituted in the assay buffer. Leptin plasma level was measured by an ELISA according to the manufacturer's instructions (Uscn Life Science, Inc., Wuhan, China).

\section{Oral glucose tolerance test in rabbits}

Oral glucose tolerance test was performed in accordance with the published method (Filippi et al. 2009, Vignozzi et al. 2011). Briefly, after an overnight fasting a 50\% glucose solution was orally administered to the rabbits, at a dose of $1.5 \mathrm{~g} / \mathrm{kg}$. Blood samples were collected 15,30 , and $120 \mathrm{~min}$ after glucose loading for blood glucose dosage. The incremental area under the curve was calculated by the Graphpad prism Software version 4.0 for Windows, as described previously (Filippi et al. 2009, Vignozzi et al. 2011).
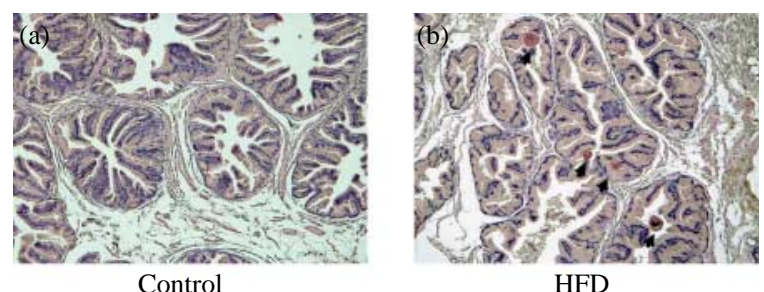

HFD

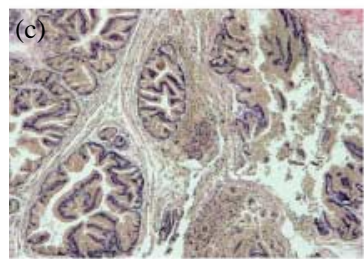

HFD

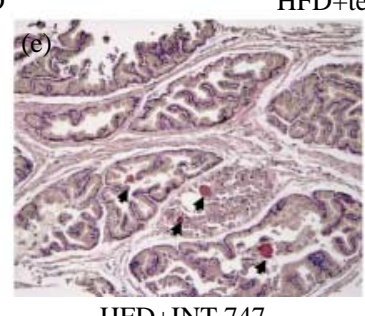

HFD+INT-747

Figure 2 Infiltrating cells and corpora amylacea in prostate sections. Prostate sections stained with hematoxylin and eosin of control (a), HFD (b and c), HFD + testosterone (d), and HFD + INT747 (e) rabbits (magnification $4 \times$ ). A normal prostate gland composed by a luminal epithelium and a thick glandular-adjacent stroma with rare infiltrating inflammatory cells was present in control (a) and testosterone-treated HFD (d) rabbits. Areas of inflammatory cells infiltration $\left(^{*}\right)$ within the periacinar stroma and $\mathrm{CA}$ (solid arrow) were frequently observed in the prostate of HFD (b and c) and INT-747-treated (e) rabbits. Images are representative of three independent experiments. 


\section{Immunohistochemistry}

Immunohistochemical studies were performed with slight modifications of previously described protocols (Penna et al. 2009). Briefly, prostate sections were incubated overnight at $4{ }^{\circ} \mathrm{C}$ or with the monoclonal mouse anti-CD45 (1:100 vol/ vol, DakoCytomation, Copenhagen, Denmark), the antimacrophage antibody RAM11 (Dako, Carpenteria, CA, USA; $1: 80 \mathrm{vol} / \mathrm{vol})$, or anti-lactoferrin $(1: 1000 \mathrm{vol} / \mathrm{vol}$, Sigma $)$ as primary antibodies. Sections were rinsed in PBS, incubated with biotinylated secondary antibody and then with streptavidinbiotin-peroxidase complex (Ultravision large volume detection system anti-polyvalent, Lab Vision, Fremont, CA, USA). Controls for antiserum specificity were performed as described previously (Filippi et al. 2009, Vignozzi et al. 2011). The reaction product was developed with the $3^{\prime}, 3^{\prime}$-diaminobenzidine tetrahydrochloride as chromogen (Sigma-Aldrich). The slides were evaluated and photographed using a Nikon MicrophotFXA microscope (Nikon, Tokyo, Japan).

Computer-assisted quantification of the staining of CD45 has been made on not hematoxylin and eosin counterstained images and after background subtraction using Adobe Photoshop 6.0 Software (Adobe Systems).

\section{Hypoxia detection in rabbit prostate}

Tissue oxygenation has been analyzed as described previously (Vignozzi et al. 2006, 2008, 2009, Morelli et al. 2010a). Briefly, $1 \mathrm{~h}$ before being killed, rabbits of each experimental group were intraperitoneally injected with the bioreductive drug pimonidazole hydrochloride (Hypoxyprobe-1,
$60 \mathrm{mg} / \mathrm{kg}$ ). Pimonidazole (hypoxyprobe) is a water soluble substituted 2-nitrominidazole that is rapidly distributed to all tissues in the body, but it only forms adducts with proteins in hypoxic cells, which are at an oxygen pressure equal to or lower than $10 \mathrm{mmHg}$. Hypoxic cells are thereafter easily detected by immunohistochemistry, using a monoclonal antibody (Hypoxyprobe-1Mab1) that recognizes hypoxyprobe protein adduct (Durand \& Raleigh 1998, Bennewith et al. 2002); Pimonidazole as a probe for the in vivo detection of hypoxia has been validated previously (Arteel et al. 1995, Vignozzi et al. 2006, 2008, 2009, Bouchentouf et al. 2008, Via et al. 2008, Morelli et al. 2010a). Rabbit ventral prostate samples were rapidly removed and fixed in $4 \%$ neutral buffered formalin, dehydrated, and embedded in paraffin. Immunohistochemical studies were performed on deparaffinized and rehydrated sections, according to the manufacturer's instructions. Briefly, slides were exposed to hypoxyprobe-1Mab1 (diluted 1:50) for $40 \mathrm{~min}$ at room temperature, rinsed in PBS and $0 \cdot 2 \%$ Brij 35 for seven times at $0{ }^{\circ} \mathrm{C}$, incubated with a biotinylated secondary antibody, and finally were incubated with streptavidin-biotin-peroxidase complex (Lab Vision Corporation). The reaction product was developed with the $3^{\prime}, 3^{\prime}$-diaminobenzidine tetrahydrochloride as chromogen (Sigma-Aldrich) and photographed using a Nikon Microphot-FXA microscope (Nikon). Computerassisted quantification of the staining has been made after background subtraction using Adobe Photoshop 6.0 Software (Adobe Systems). Some tissue sections were stained with hematoxylin and eosin or with Masson's trichrome (Bio-Optica, Milan, Italy) as described previously (Vignozzi (a)
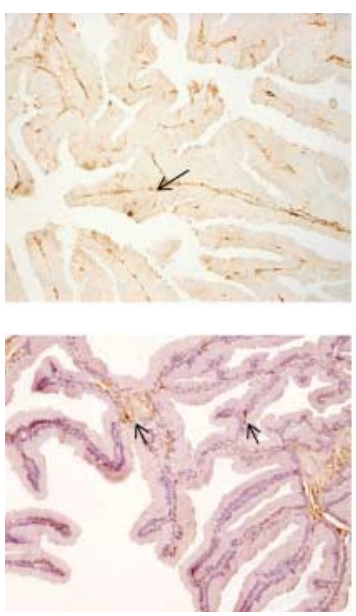

Control
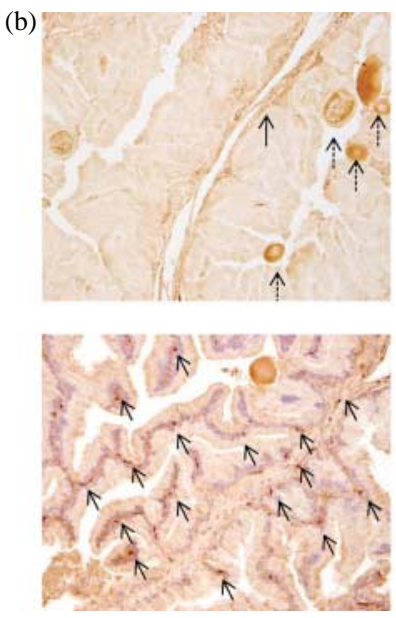

HFD
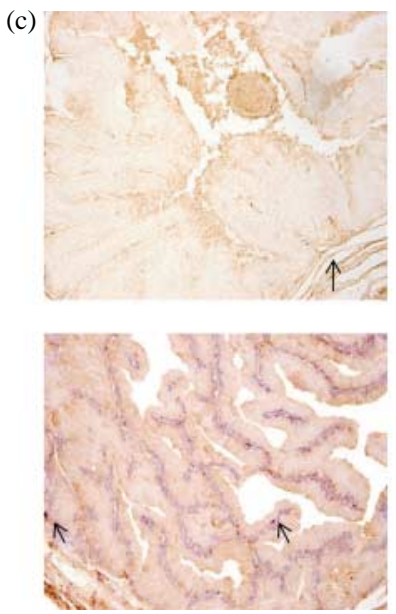

HFD+testosterone
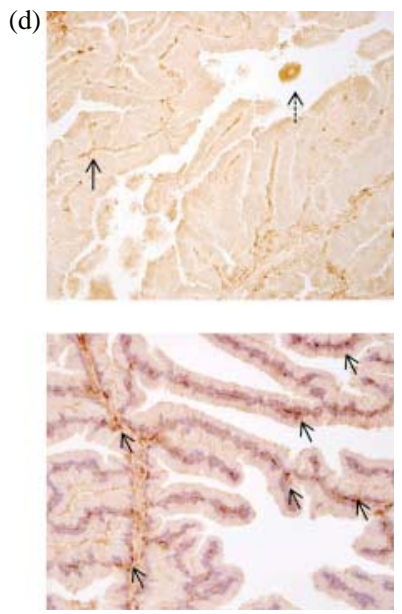

HFD+INT-747

Figure 3 Immunostaining for lactoferrin and RAM11 in rabbit prostate. Upper panels (magnification 10×): immunohistochemical analysis of prostate sections stained with lactoferrin. Control (a) and testosterone-treated HFD (c) show only scanty positivity for lactoferrin within the stroma (solid arrow) while HFD (b) and INT-747-treated (d) rabbits show an intense staining in both CA (dashed arrow) and stroma (solid arrow). CA staining was positive for lactoferrin with areas of dense staining and concentric rings that do not stain positive. Lower panels (magnification $10 \times$ ): immunohistochemical analysis of prostate sections stained with RAM11 and hematoxylin counterstained. Control (a) and testosterone-treated HFD (c) are almost unstained, while HFD (b) and INT-747-treated (d) rabbits show intense staining in stromal compartments (arrows). Images are representative of three independent experiments. 

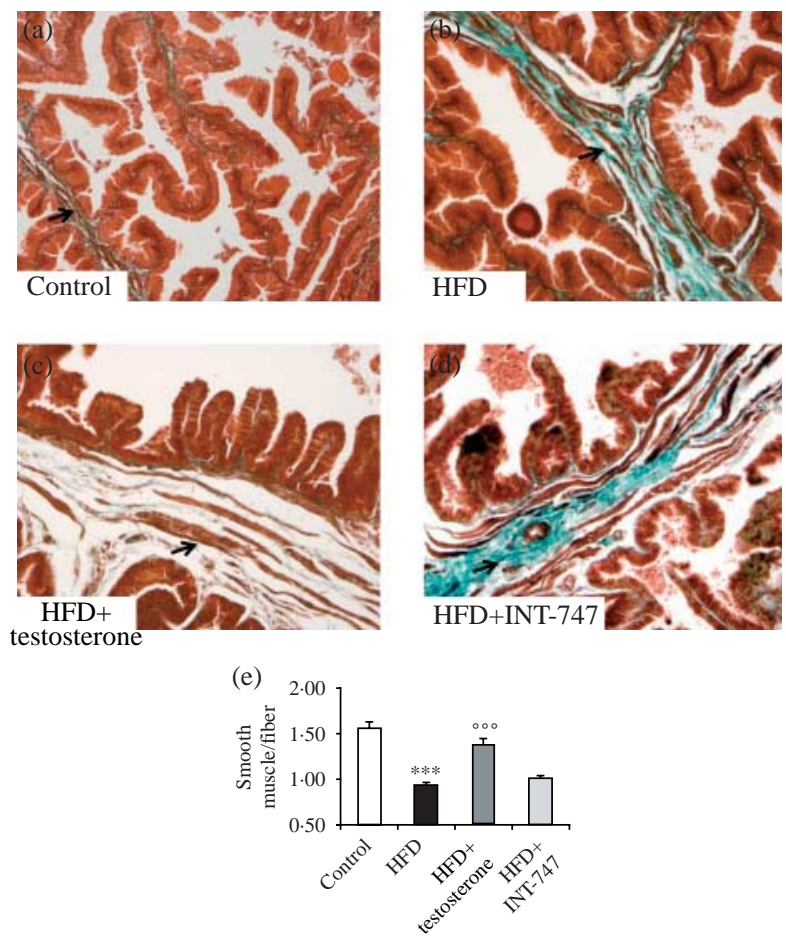

Figure 4 Testosterone treatment inhibits fibrosis in HFD rabbit prostate sections. Smooth muscle fibers are stained in red and collagen fibers in blue by Masson's trichrome staining (magnification $10 \times$ ). (a) Control rabbits: smooth muscle cells are prevalent in the periacinar stromal layer (arrows). (b) HFD rabbits: a clear increase in collagen fibers is present in the stromal space. (c) HFD + testosterone rabbits: smooth muscle loss is essentially prevented and fibrosis limited. (d) HFD + INT-747 rabbits: HFDinduced increase in collagen fibers was not prevented by INT-747 treatment. (e) Computer-assisted quantitative image analysis of three independent experiments ( $n=3$ for each group). ${ }^{* * *} P<0 \cdot 001$ vs control and ${ }^{000} P<0.001$ vs HFD.

et al. 2006). The images were imported into Adobe Photoshop 6.0 Software (Adobe Systems) and then split into their red, green, and blue staining components by selecting RGB color feature of Adobe Photoshop 6.0 Software. To measure the red (smooth muscle fibers) and blue (collagen fibers) staining components of the interductal stroma, the epithelial layer was omitted from the analysis by the computer-assisted manual delineation of regions of interest. Histograms of the individual components of the RGB images were then calculated and reported as red/blue ratio.

\section{$R N A$ extraction and quantitative RT-PCR analysis}

Isolation of RNA from frozen rabbit tissues was performed by Trizol reagents according to the manufacturer's instructions (Invitrogen S.r.l). cDNA synthesis was carried out using the RT kit purchased from Applied Biosystems (Foster City, CA, USA), as described previously (Filippi et al. 2009, Vignozzi et al. 2011). Quantitative RT-PCR (qRT-PCR) was performed by SYBR Green Real-time PCR Master Mix (Applied Biosystems) with the following thermal cycler conditions: 40 cycles at $95^{\circ} \mathrm{C}$ for $30 \mathrm{~s}$ and $60{ }^{\circ} \mathrm{C}$ for $1 \mathrm{~min}$ followed by dissociation curve analysis to verify the primer specificity. Specific primers were designed on rabbit sequences available at NCBI GenBank (http://www.ncbi. nlm.nih.gov) or Ensemble Genome (http://www.ensembl. org), or based on homology to the human sequence. The primer sequences used are reported in Table 1. Amplification and detection were performed with the ABI Prism 7900HT Fast Real-time PCR System (Applied Biosystems). The expression of $18 \mathrm{~S}$ rRNA subunit, chosen as reference gene, was quantified with a predeveloped assay (Applied Biosystems) and used for normalization and relative quantitation of the target genes. The analysis of the results was based on the comparative cycle threshold method according to the manufacturer's instructions (Applied Biosystems), as described previously (Filippi et al. 2009, Vignozzi et al. 2011).
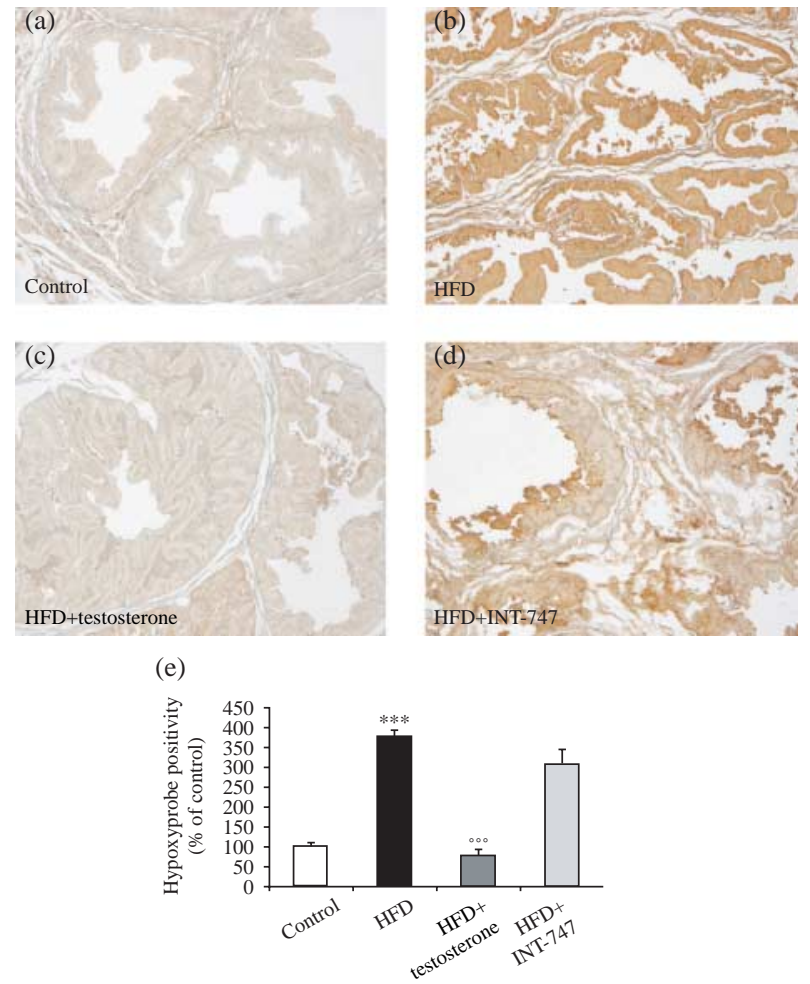

Figure 5 Testosterone treatment inhibits hypoxia in HFD rabbit prostate. Hypoxyprobe adducts were revealed in hypoxic cells (PO2 $<10 \mathrm{mmHg}$ ) of prostate transverse sections by a monoclonal antibody (magnification $4 \times$ ). (a) Control rabbits: only scanty positive labeling is present. (b) HFD rabbits: massive hypoxia is present in both the epithelium and stroma. (c) Testosterone-treated HFD rabbits: hypoxyprobe labeling is markedly decreased. (d) INT747-treated rabbits a severe hypoxia is present in both the epithelial and stromal compartments. (e) Computer-assisted quantitative image analysis of three independent experiments $(n=3$ for each group). Control optical density was taken as $100 \%$. ${ }^{* * *} P<0 \cdot 001$ vs control and ${ }^{\circ 00} \mathrm{P}<0.001$ vs HFD. 


\section{Statistical analysis}

Statistical analysis was performed with one-way ANOVA test followed by Tukey-Kramer post-hoc analysis, and $P<0 \cdot 05$ was considered significant. Maximal inhibitory effect $\left(\mathrm{I}_{\max }\right)$ and half-maximal response inhibiting concentration $\left(\mathrm{IC}_{50}\right)$ values were calculated using the computer program ALLFIT (De Lean et al. 1978). The same program was used to statistically analyze differences in sigmoidal dose-response curves. Correlations were assessed by the Spearman's method and statistical analysis was performed on Statistical Package for the Social Sciences (SPSS; SPSS, Inc., Chicago, IL, USA) for Windows 15.0.

\section{Results}

Characterization of HFD-induced MetS features and histological prostate correlates

Biochemical and physical effects of feeding rabbits a HFD for 12 weeks are reported in Table 2. HFD induced a significant increase in mean arterial pressure, lipids, visceral fat, and glucose intolerance, as demonstrated by the area under the curve of the oral glucose tolerance test. Conversely, body weight was not affected (Table 2). Accordingly, in a preliminary investigation, leptin levels were not different in MetS (44.91 $\pm 2 \cdot 8, n=10)$ compared with control rabbit $(44 \cdot 79 \pm 2 \cdot 7, n=8, P=0 \cdot 93)$.

Figure 1 (CD45 staining) and Fig. 2 (hematoxylin-eosin) show the effect of HFD-associated MetS on prostate histology. CD45-round positive cells were extensively present in both interductal stroma and intertwined within the epithelial glands. Numerous CD45-round positive cells were also present within the glandular lumen often associated with corpora amylacea (see below). Computer-assisted image analysis indicated a highly positive increase in CD45 staining in MetS rabbits $(P<0 \cdot 0001)$.

Overt hypogonadism was induced by HFD-associated MetS, and characterized by low testosterone along with prostate, seminal vesicle, and testis hypotrophy (see Table 2).

\section{Effect of HFD and hormonal supplementation on MetS and prostate histological features}

In HFD rabbits, testosterone supplementation not only restored testosterone plasma levels and prostate and seminal vesicles weight, but also normalized fasting glucose, glucose tolerance, and dramatically decreased visceral fat (Table 2). HFD-induced dyslipidemia was not affected by testosterone treatment, while mean arterial pressure was reduced (Table 2).
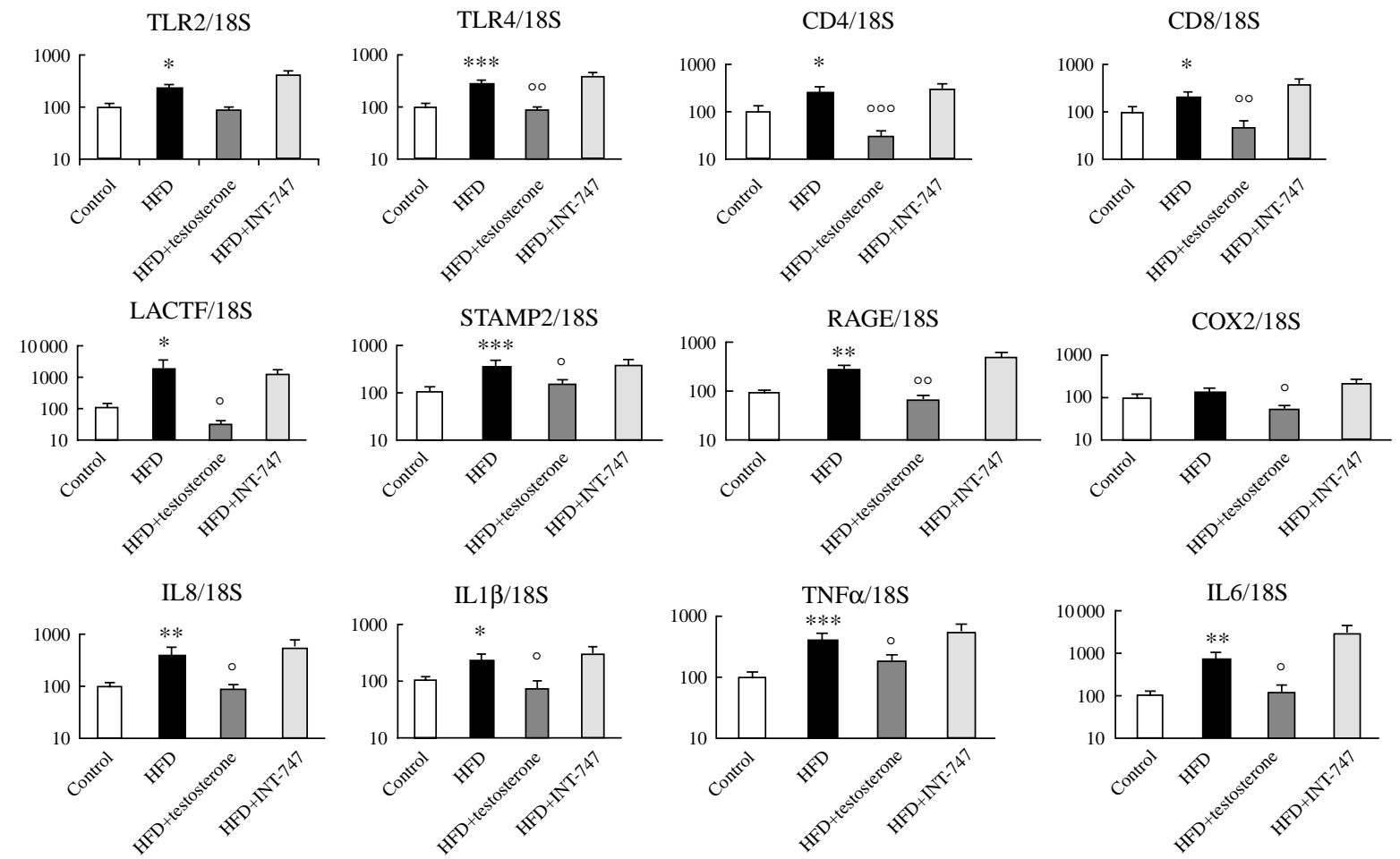

Figure 6 Testosterone treatment inhibits expression of inflammatory markers in rabbit prostate. Relative mRNA expression of inflammatory markers was evaluated using quantitative RT-PCR in prostate sample from control $(n=13)$, HFD $(n=9)$, HFD+ testosterone $(n=9)$, and HFD + INT-747 $(n=11)$. Data were calculated according to comparative $C_{\mathrm{t}}$ method by rRNA subunit $18 \mathrm{~S}$ as the reference gene for normalization. Results are expressed in percentage over control and are reported as mean \pm S.E.M. on a logarithmic scale graph. ${ }^{*} P<0 \cdot 05,{ }^{* *} P<0 \cdot 01$, and ${ }^{* * *} P<0 \cdot 001$ vs control and ${ }^{\circ} P<0 \cdot 05,{ }^{\circ} P<0 \cdot 01$, and ${ }^{\circ 00} P<0 \cdot 001$ vs HFD. 

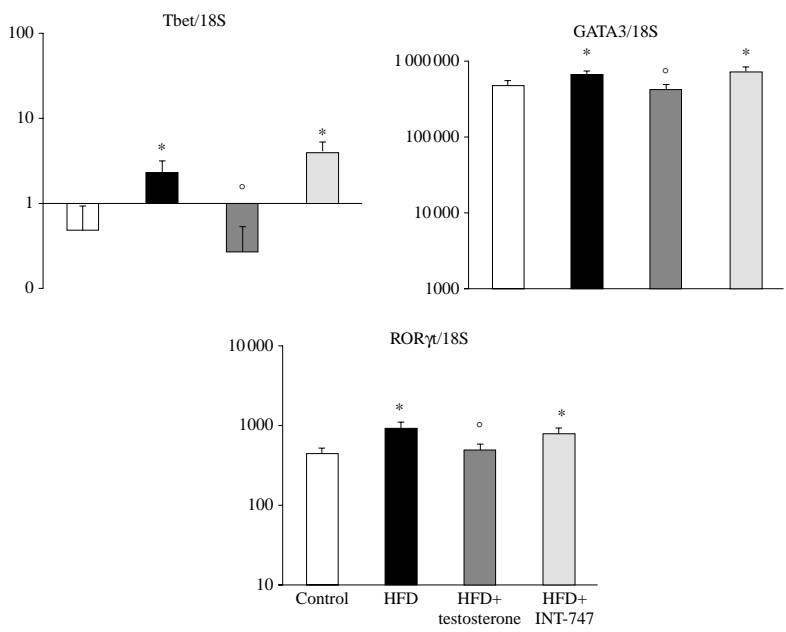

Figure 7 Testosterone treatment modulates expression of $\mathrm{T}$ cell lineage-determining transcription factors in rabbit prostate. The mRNA expression of transcription factors Tbet, GATA3, and ROR $\gamma \mathrm{t}$ was evaluated using quantitative RT-PCR in prostate sample from control $(n=9), \operatorname{HFD}(n=8), \operatorname{HFD}+$ testosterone $(n=9)$, and HFD+ INT-747 $(n=8)$. Data were calculated according to comparative $C_{\mathrm{t}}$ method by rRNA subunit $18 \mathrm{~S}$ as the reference gene for normalization. Results are expressed in percentage over control and are reported as mean \pm s.E.M. on an arithmetic scale graph. ${ }^{*} P<0.05$ vs control and ${ }^{\circ} P<0 \cdot 05$ vs HFD.

Similarly, dosing INT-747 significantly ameliorated several MetS features (see Table 2). No leukocyte esterase and nitrites were detected in urine, suggesting no urinary infections (not shown).

Hematoxylin-eosin staining of prostate from HFD confirms a diffuse inflammatory cell infiltration, localized in the interductal stroma, and glandular epithelial cells with the presence of corpora amylacea (CA), within the acinar lumen (Fig. $2 \mathrm{~b}$ and $\mathrm{c}$ ). In contrast, prostate from both HFD+ testosterone (Fig. 2d) and controls (Fig. 2a) showed no alterations. INT-747 did not prevent these HFD-induced abnormalities (Fig. 2e).

To better study inflammatory prostate infiltrates, we immunostained for the neutrophil marker lactoferrin and the macrophage marker RAM11 (Fig. 3). CA stained very strongly for lactoferrin, showing an unstained ring structure, as expected (Sfanos et al. 2009). Prostate from control and HFD + testosterone showed scanty positivity for lactoferrin (Fig. 3, upper panels). Anti-macrophage specific antibody RAM11 revealed a predominant staining within the prostatic interductal stroma of the HFD and HFD + INT-747 groups. In the HFD + testosterone, a reduced macrophage infiltration was observed (Fig. 3, lower panels).

Figure $4 \mathrm{a}-\mathrm{d}$ shows Masson's trichrome staining, to evaluate fibrosis. Histomorphometric analysis (Fig. 4e) indicated that the muscle/fiber ratio was reduced by HFD $(P<0.001$ vs control) and was completely rescued by testosterone $(1 \cdot 4 \pm$ $0 \cdot 7, P<0 \cdot 001$ vs HFD, and $P=0.06$ vs control). Conversely, HFD + INT-747 did not affect fibrosis.
Prostate oxygenation was also examined (Fig. 5). In control rabbits, only scanty cells reacted with the hypoxyprobe (Fig. 5a). HFD dramatically increased immunopositivity in the epithelium and in fibromuscular stroma (Fig. 5b). Testosterone, but not INT-747, supplementation almost completely prevented hypoxygenation (Fig. $5 \mathrm{c}$ and d). Image analysis is in Fig. 5e.

\section{$m R N A$ expression of inflammatory and fibrosis/myofibroblast markers in the prostate}

Using qRT-PCR, we observed a marked upregulation of inflammatory markers in prostate from HFD (Fig. 6). HFD induced an increase of testosterone lymphocyte (CD4 and CD8), neutrophil (lactoferrin), antigen presenting cells, leukocytes, regulatory testosterone lymphocyte (toll-like receptor 2 (TLR2), TLR4, six transmembrane protein of prostate 2 (STAMP2)), and inflammation (cyclooxygenase-2, receptor for advanced glycation endproducts (RAGE)) markers as well as IL8, IL1 $\beta$, IL6, and tumor necrosis factor $\alpha$ (TNF $\alpha$; Fig. 6). To characterize $\mathrm{CD}^{+}{ }^{+} \mathrm{T}$ lymphocyte subsets, expression of specific transcription factors namely
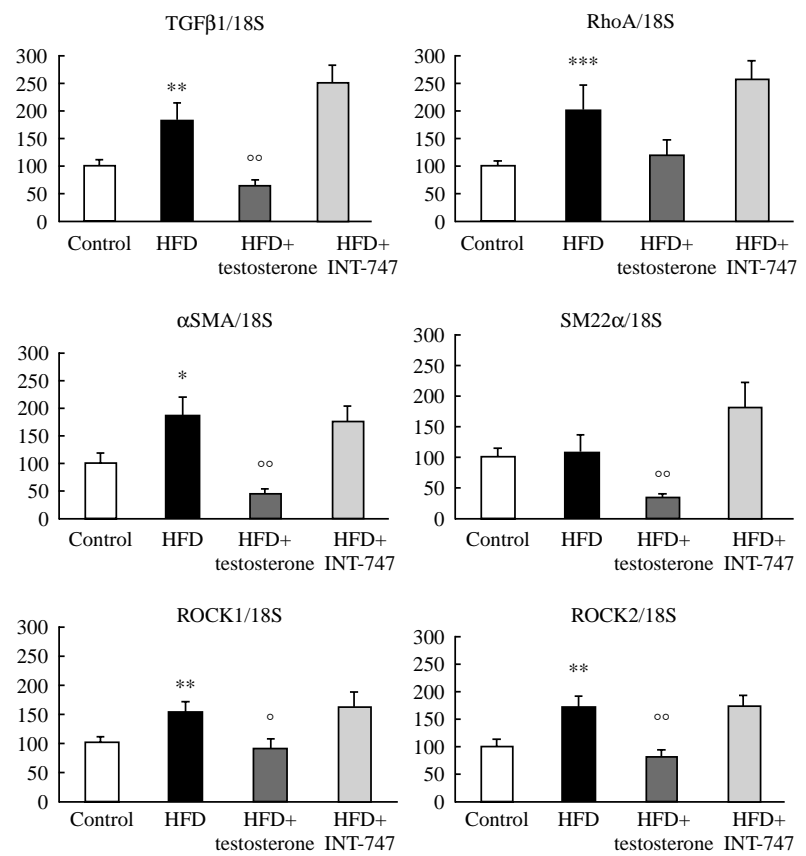

Figure 8 Testosterone treatment inhibits expression of fibrosis and myofibroblast transdifferentiation markers in rabbit prostate. Relative mRNA expression of fibrosis and myofibroblast transdifferentiation markers was evaluated using quantitative RT-PCR in prostate sample from control $(n=15), \operatorname{HFD}(n=9), \mathrm{HFD}+$ testosterone $(n=9)$, and HFD+INT-747 $(n=11)$. Data were calculated according to comparative $C_{\mathrm{t}}$ method by rRNA subunit $18 \mathrm{~S}$ as the reference gene for normalization. Results are expressed in percentage over control and are reported as mean \pm s.E.M. on a logarithmic scale graph. ${ }^{*} P<0 \cdot 05,{ }^{* *} P<0 \cdot 01$, and ${ }^{* * *} P<0.001$ vs control and ${ }^{\circ} P<0.05$ and ${ }^{\circ} P<0 \cdot 01$ vs HFD. 
(a)

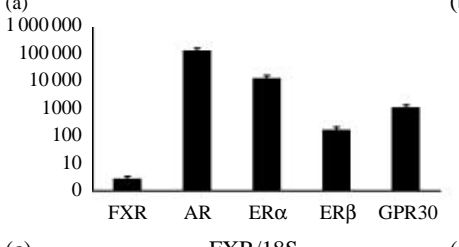

(c)

(e)

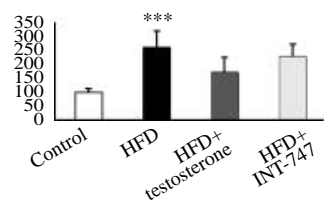

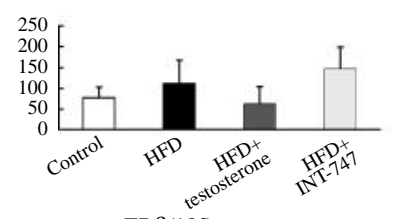

(b)

(d)

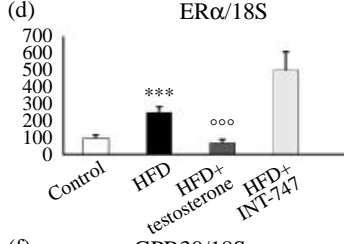

(f)

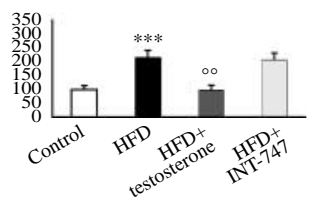

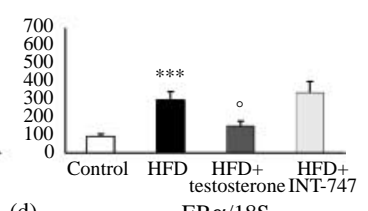

Figure 9 Relative mRNA expression of sex steroid receptors and FXR in rabbit prostate. The mRNA expression of sex steroid receptors and FXR was evaluated using quantitative RT-PCR in the rabbit ( $\mathrm{a} ; n=15)$ prostate. Results are expressed as arbitrary units after normalization over 18S rRNA subunit by the comparative $C_{t}$ method and are reported as mean \pm S.E.M. on a logarithmic scale graph. The AR (b), FXR (c), ER $\alpha(d)$, and ER $\beta(e)$ mRNA expression in prostate sample from control $(n=13), \operatorname{HFD}(n=9), \operatorname{HFD}+$ testosterone $(n=9)$, and HFD + INT-747 $(n=11)$ are also reported. Results are expressed in percentage over control and are reported as mean \pm S.E.M. on an arithmetic scale graph. $* * * P<0 \cdot 001$ vs control and ${ }^{\circ} P<0 \cdot 05,{ }^{\circ} P<0 \cdot 01$ and ${ }^{\circ \circ} P<0.001$ vs HFD vs HFD.

T-box transcription factor 3 (Tbet), retinoic acid receptorrelated orphan receptor $\gamma \mathrm{t}(\mathrm{ROR} \gamma \mathrm{t}$ ) and GATA-binding protein 3 (GATA3; markers for T helper type 1 (Th1), Th17, and Th2 respectively). In control rabbits, a constitutive high expression of GATA3 and ROR $\gamma$ t was detected, whilst Tbet was absent. HFD increased GATA3 and ROR $\gamma \mathrm{t}$ and induced Tbet (Fig. 7). Testosterone, but not INT-747, treatment prevented all these changes (Figs 6 and 7).

As shown in Fig. 8, HFD upregulated the expression of fibrosis and myofibroblast activation markers, including transforming growth factor $\beta$ (TGF $\beta 1), \alpha$-smooth muscle actin ( $\alpha \mathrm{SMA}), \mathrm{R}$ as homolog gene family, member A (RhoA), Rho-associated coiled coil-containing kinase type 1 (ROCK1), and type 2 (ROCK2). This induction was prevented by testosterone, but not by INT-747, treatment (Fig. 8).

\section{Sex steroid receptors and FXR expression}

Figure 9a shows the mRNA expression of sex steroid receptors and FXR in rabbit prostate. Androgen receptor (AR) showed the highest, and FXR the lowest expression. HFD increased mRNA expression of AR, estrogen receptor $\alpha(\operatorname{ER} \alpha), \operatorname{ER} \beta$, and GPR30 (Fig. 9b-f). AR, ER $\alpha$, and
GPR30 induction was completely counteracted by testosterone, but not by INT-747, treatment. In contrast, FXR gene expression was not affected by any treatment (Fig. 9c).

Sex steroid plasma levels and their association with fibrosis/myofibroblast and inflammation markers

Figure 10 shows $\mathrm{E}_{2}$ (Fig. 10a) along with the testosterone (see Table 2)/ $\mathrm{E}_{2}$ ratio (Fig. 10b) as derived from immunoassays, after diethyl ether extraction. MetS was associated with a fall in testosterone and a rise in $\mathrm{E}_{2}$, which were restored by testosterone dosing. INT-747 normalized estrogen, but not androgen level (see Fig. 10a, Table 2). Accordingly, testosterone $/ \mathrm{E}_{2}$ ratio was normalized but testosterone but not INT-747 treatment (Fig. 10b). Visceral adiposity was negatively associated with plasma levels of testosterone ( $r=-0 \cdot 317, n=119, P<0 \cdot 0001$, not shown), testosterone/ $\mathrm{E}_{2}$ ratio $(r=-0 \cdot 277, n=116, P<0 \cdot 01$, see also Fig. $10 \mathrm{c})$, and positively with $\mathrm{E}_{2}(0 \cdot 256, n=116, P<0 \cdot 01$, not shown). Testosterone $/ \mathrm{E}_{2}$ ratio was negatively associated with all the aforementioned markers of fibrosis (see Fig. 10d-i) and several of inflammation (Table 3).

\section{Discussion}

This study demonstrates that HFD-induced MetS is associated with hypogonadism and a prostatitis-like syndrome, characterized by prostatic inflammation, hypoxia, and fibrosis. All these features are markedly counteracted by testosterone supplementation. Hence, testosterone prevents (and not induces) prostatic diseases.

Recently, we have established a non-genomic model of MetS, by exposing rabbits to an HFD for 12 weeks. HFD induces hyperglycemia, glucose intolerance, hypercholesterolemia, hypertriglyceridemia, hypertension, and increased visceral fat mass along with hypogonadotropic hypogonadism (Filippi et al. 2009, Vignozzi et al. 2011). Hence, HFD in rabbits recapitulates the clinical phenotype of human male MetS. In this study, we report an additional novel feature of HFD-induced MetS in rabbits: a prostatitis-like inflammation.

The inflammation was characterized by infiltration of inflammatory cells and formation of corpora amylacea. Corpora amylacea are protein aggregates of lactoferrin (Sfanos et al. 2009), delivered by neutrophils following acute prostate inflammation (Legrand et al. 2005, Sfanos et al. 2009). As expected (De Marzo et al. 2007, Sfanos et al. 2009, Yanamandra et al. 2009), we have observed corpora amylacea adjacent to infiltrating inflammatory cells. Gene expression of macrophage, neutrophil, and $\mathrm{CD}^{+}$and $\mathrm{CD}^{+} \mathrm{T}$ lymphocyte markers were increased by HFD. The increased expression of TLR2, TLR4 mRNA - widely distributed not only in immune but also in non-professional antigen presenting cells, such as stromal prostatic cells (Fibbi et al. 2010) - suggests the activation of both innate and specific immune responses. Recent studies have shown that 

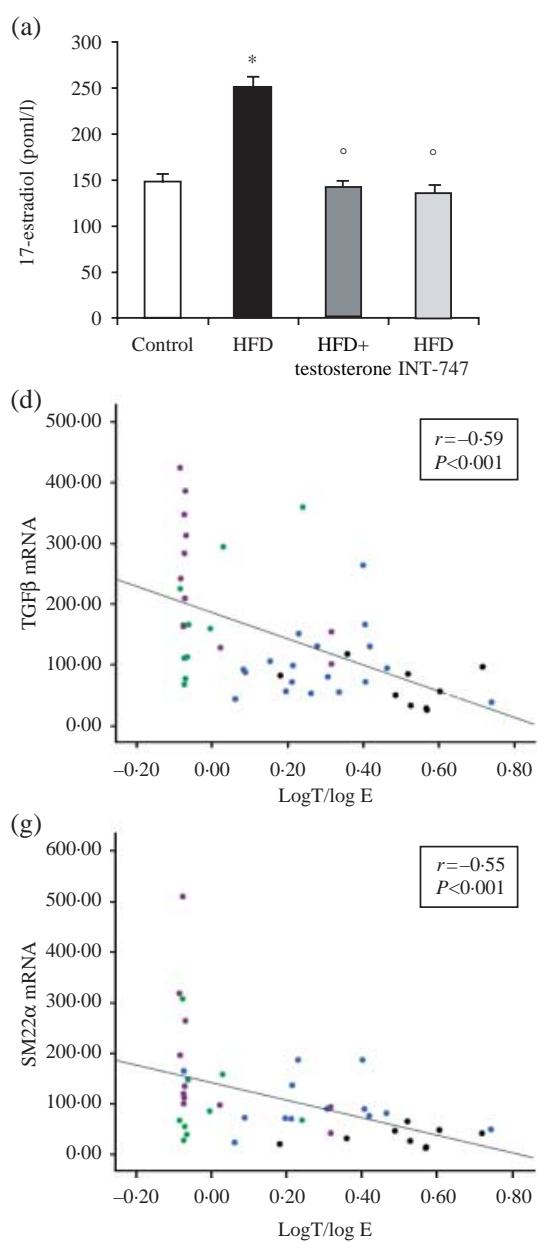

(b)

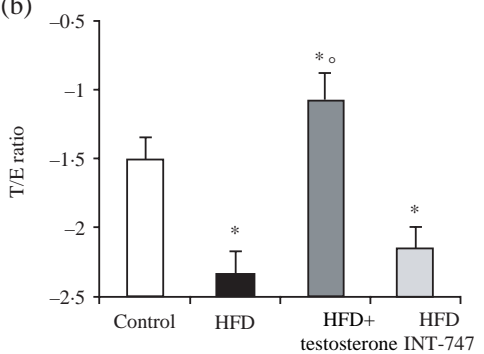

(e)

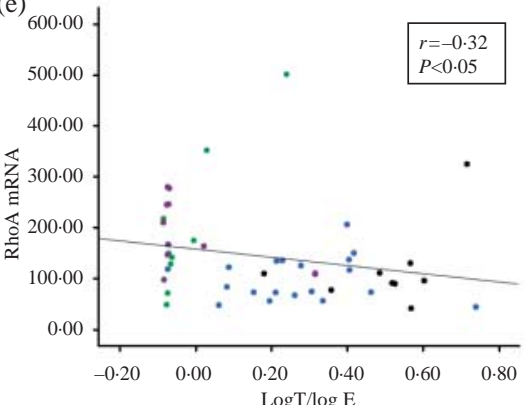

(h)

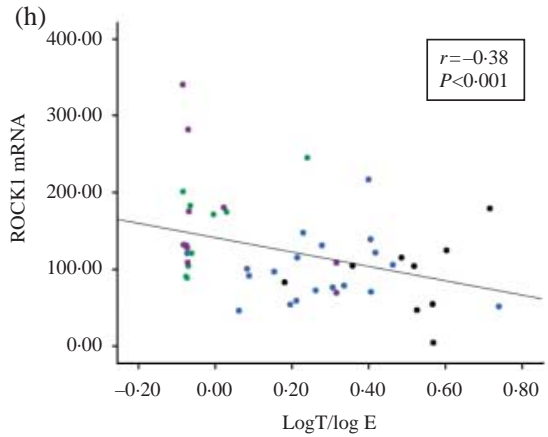

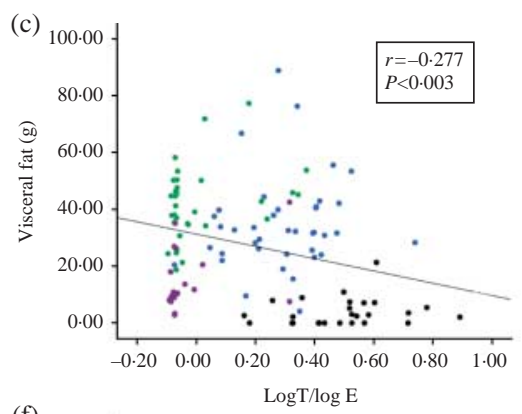

(f)
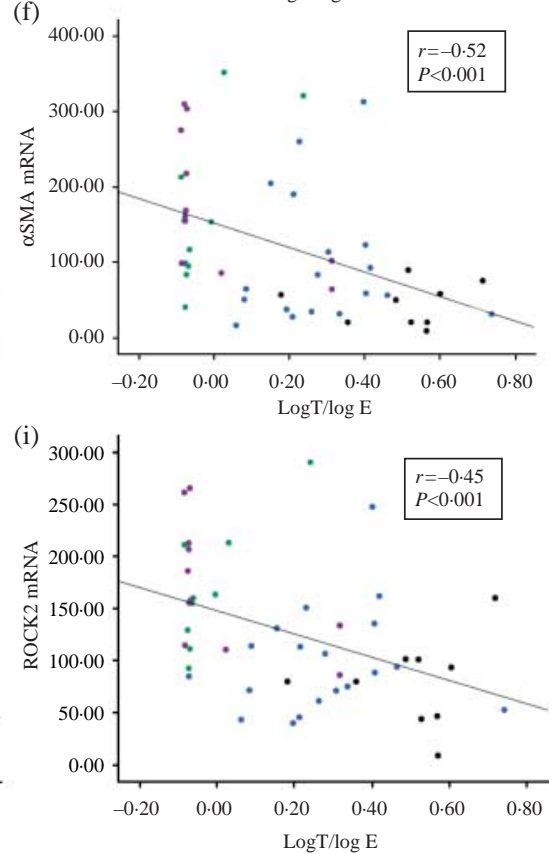

Figure 10 Effect of HFD on $17 \beta$-estradiol $\left(E_{2}\right)$ plasma level and testosterone/ $E_{2}$ ratio. Plasma levels of $E_{2}(a)$ and testosterone/ $E_{2}(T / E)$ ratio (b) in the different experimental groups. ${ }^{*} P<0 \cdot 0001 \mathrm{vs}$ control and ${ }^{\circ} P<0 \cdot 0001$ vs HFD. (c) Relationship between the testosterone/ $\mathrm{E}_{2}$ (expressed as (log T/log E); abscissa) and the amount of visceral fat (ordinate) as derived from univariate Spearman's regression analysis. (d-i) Relationship between the testosterone/ $\mathrm{E}_{2}$ (expressed as $(\log \mathrm{T} / \log \mathrm{E})$; abscissa) and the markers of fibrosis (ordinate) as derived from univariate Spearman's regression analysis. The relative $r(. r)$ and level of significance $(P)$ are reported within the panels. Control, blue circle; HFD, green circle; HFD + testosterone, black circle; HFD + INT-747, purple circle.

TLR2, TLR 4 can play an important role in initiating a proinflammatory cascade, even in clinical settings in which microbial ligands are not present (Lorne et al. 2010). Indeed, in our model of MetS-associated prostate inflammation, no nitrites and leukocyte esterase were detected in the urine.

The STAMP2 and RAGE mRNAs - abundantly expressed in macrophages (Sims et al. 2010, Wang et al. 2010) and upregulated by cytokines (IL1 $\beta$, IL6, TNF $\alpha$ ) and chemokines (IL8) - are also overexpressed in HFD prostate.

$\mathrm{CD}^{+}{ }^{+}$and $\mathrm{CD}^{+}{ }^{\mathrm{T}}$ lymphocytes are also present in the prostatic infiltrates of HFD. On the basis of the cytokine produced and on the functions exhibited, CD $4{ }^{+} \mathrm{T}$ helper cells can be distinguished into three distinct effector subpopulations: Th1, Th2, and Th17, based on stable expression of specific transcription factors Tbet, ROR $\gamma \mathrm{t}$, and GATA3 respectively (Zhu et al. 2010). In the prostate from control, we detected a constitutive high expression of GATA3 and ROR $\gamma t$, whilst Tbet was absent. HFD was associated with an increase in both Th2- and Th17-transcription factors and to a peculiar induction of Tbet expression. Expansion of Th1 and Th17 effector cells has been found associated with BPH development (Fibbi et al. 2010).

Collectively, our data suggest that both acute and chronic inflammation are present in prostate samples from HFDtreated rabbits.

Beside inflammation, severe fibrosis - with myofibroblast activation - and hypoxia were peculiar features of HFD prostate. Prostate ischemia, along with inflammation and stromal reorganization - characterized by fibroblast trans-differentiation to myofibroblasts - has recently been recognized as a key pathogenetic factors in the development of both experimental and clinical LUTS (Andersson et al. 2011). 
Table 3 Association between $\log \mathrm{T} / \log \mathrm{E}$ ratio and gene expression of inflammatory markers

\begin{tabular}{|c|c|c|c|}
\hline & $r$ & $n$ & $\boldsymbol{P}$ \\
\hline TLR2 & $-0 \cdot 47$ & 47 & $0 \cdot 001^{*}$ \\
\hline TLR4 & -0.52 & 48 & $0 \cdot 000^{*}$ \\
\hline CD4 & -0.56 & 42 & $0 \cdot 000^{*}$ \\
\hline CD8 & -0.63 & 42 & $0 \cdot 000^{*}$ \\
\hline LACTF & -0.53 & 42 & $0.000^{*}$ \\
\hline STAMP2 & $-0 \cdot 32$ & 42 & $0.038^{*}$ \\
\hline$R A G E$ & $-0 \cdot 71$ & 42 & $0.000^{*}$ \\
\hline$C O X 2$ & $-0 \cdot 48$ & 48 & $0 \cdot 001 *$ \\
\hline IL8 & $-0 \cdot 34$ & 47 & $0 \cdot 018^{*}$ \\
\hline$I L 1 \beta$ & $-0 \cdot 36$ & 47 & $0 \cdot 012^{*}$ \\
\hline$T N F \alpha$ & $-0 \cdot 26$ & 46 & 0.079 \\
\hline IL6 & $-0 \cdot 41$ & 48 & $0.004 *$ \\
\hline T-bet & -0.52 & 38 & $0.001 *$ \\
\hline GATA3 & $-0 \cdot 42$ & 38 & $0.009^{*}$ \\
\hline$R O R \gamma t$ & $-0 \cdot 17$ & 38 & $0 \cdot 317$ \\
\hline
\end{tabular}

Correlations $(r)$ and level of significance $(P)$ are derived from univariate analysis. $n$ indicates the number of samples. Asterisk indicates statistical significance. See legend to Table 1 for gene abbreviations.

In different tissues (Kardassis et al. 2009), including prostate (Fibbi et al. 2010), an interplay of TGF $\beta$ and RhoA/ROCK signaling have been recognized at the crossroads of inflammatory response and fibrosis. Consistent with this view, expression of TGF $\beta$ and RhoA/ROCK is upregulated in HFD prostate.

The most striking feature of our study is that testosterone supplementation normalizes all the aforementioned HFDinduced prostatic alterations, including inflammation, hypoxia, and fibrosis. An anti-inflammatory effect of testosterone in castration-induced prostate inflammation was previously reported (Robinette 1988, Tangbanluekal \& Robinette 1993, Quintar et al. 2006, Yatkin et al. 2009). Androgens therefore act as endogenous inhibitors of immune responses, even in the prostate, as already reported for other autoimmune processes (Ansar Ahmed et al. 1986, Fox 1992, Harbuz et al. 1995, Fijak et al. 2011). Although our data showing that testosterone supplementation reduces the expression of pro-inflammatory cytokines are consistent with previous studies (Bebo 1999, Liva \& Voskhul 2001, Fijak et al. 2011), the precise mechanisms of testosteronemediated immunomodulation are still unknown.

Testosterone supplementation - in parallel with its beneficial effects on the prostate - ameliorates also several MetS features. Hence, its beneficial effect on prostate could be mediated by the favoring effect on some MetS component. However, experiments with INT-747 deny this hypothesis. INT-747 is a FXR agonist that in this animal model counteracts, as well as testosterone, several MetS features (Vignozzi et al. 2011). However, INT-747 dosing, at variance with testosterone, did not ameliorate prostate inflammation, fibrosis, and hypoxia. These differential effects of the two hormones on prostate can be explained by the prostatic expression of their cognate receptors: high for $\mathrm{AR}$ and low for FXR. However, testosterone ameliorates also HFD-induced hypertension, whereas INT-747 does not. Hence, the positive effect of testosterone on prostate gland could be mediated by a reduction in mean arterial pressure.

As described in humans (Corona et al. 2011a), MetS in rabbit was associated with a decline in testosterone and a rise in estrogen levels, which was normalized by testosterone, but not INT-747, dosing. As expected (Corona et al. 2009, Zitzmann 2009, Corona et al. 2011a,b, Traish et al. 2011), sex steroid modifications were tightly associated with visceral fat accumulation. The ratio between testosterone and $\mathrm{E}_{2}$ retains a significant, negative, association with all the fibrosis, and the majority of inflammatory markers analyzed. Although association does not mean causality, it is possible to speculate that a local, prostatic, decline in testosterone, and/or a rise in estrogen might be responsible for prostatic derangements observed in Mets. Further studies in isolated cells are necessary to clarify this point and to identify the role of androgen and/or estrogen in MetS-associated prostate inflammation.

In conclusion, our data suggest that testosterone supplementation could have a beneficial effect on prostate health, counteracting MetS-associated prostatic alterations such as inflammation, hypoxia, and fibrosis, key components in the development and progression of BPH/LUTS. Our findings clarify pathogenetic links between MetS and prostate inflammation, and offer new perspectives for prevention and intervention in BPH/LUTS.

\section{Declaration of interest}

L V, A M, E S, P C, S F, I C, E M, M G, S S, M C, M-P P, G B V have nothing to declare. M M is a scientific consultant for Bayer Pharma AG, Germany, EliLilly Indianapolis, Indiana; Intercept Pharmaceuticals Italia Perugia, Italy; F S is an employee of Bayer Pharma AG, Berlin, Germany. L A is an employee of Intercept Pharmaceuticals Italia Perugia, Italy.

\section{Funding}

This study was supported by PRIN (Programmi di ricerca di Rilevante Interesse Nazionale) funds by the Italian Minister of University, Research and Instruction (prot number: 2009WLNXNT_002), by FIRB (Fondo per gli investimenti alla ricerca di base) funds by the Italian Minister of University, Research and Instruction (prot number: 2010RBFR10VJ56_002), and by Under40-Young Investigators funds from Italian Minister of Health (grant no. GR2008-1137632).

\section{Acknowledgements}

The authors thank Dr Gianni Rizzo for technical support to the study.

\section{References}

Amano T, Imao T, Takemae K, Iwamoto T \& Nakanome M 2010 Testosterone replacement therapy by testosterone ointment relieves lower urinary tract symptoms in late onset hypogonadism patients. Aging Male $\mathbf{1 3}$ 242-246. (doi:10.3109/13685538.2010.487552) 
Andersson KE, de Groat WC, McVary KT, Lue TF, Maggi M, Roehrborn CG, Wyndaele JJ, Melby T \& Viktrup L 2011 Tadalafil for the treatment of lower urinary tract symptoms secondary to benign prostatic hyperplasia: pathophysiology and mechanism(s) of action. Neurourology and Urodynamics 30 292-301. (doi:10.1002/nau.20999)

Ansar Ahmed S, Young PR \& Penhale WJ 1986 Beneficial effect of testosterone in the treatment of chronic autoimmune thyroiditis in rats. Journal of Immunology 136 143-147.

Arteel GE, Thurman RG, Yates JM \& Raleigh JA 1995 Evidence that hypoxia markers detect oxygen gradients in liver: pimonidazole and retrograde perfusion of rat liver. British Journal of Cancer 72 889-895. (doi:10.1038/bjc. 1995.429)

Bebo BF Jr 1999 Androgens alter the cytokine profile and reduce encephalitogenicity of myelin-reactive T cells. Journal of Immunology 162 35-40.

Bennewith KL, Raleigh JA \& Durand RE 2002 Orally administered pimonidazole to label hypoxic tumor cells. Cancer Research $\mathbf{6 2}$ 6827-6830.

Bouchentouf M, Benabdallah BF, Bigey P, Yau TM, Scherman D \& Tremblay JP 2008 Vascular endothelial growth factor reduced hypoxia-induced death of human myoblasts and improved their engraftment in mouse muscles. Gene Therapy 15 404-414. (doi:10.1038/sj.gt. 3303059)

Corona G, Mannucci E, Forti G \& Maggi M 2009 Hypogonadism, ED, metabolic syndrome and obesity: a pathological link supporting cardiovascular diseases. International Journal of Andrology 32 587-598. (doi:10.1111/j.1365-2605.2008.00951.x)

Corona G, Monami M, Rastrelli G, Aversa A, Tishova Y, Saad F, Lenzi A, Forti G, Mannucci E \& Maggi M 2011a Testosterone and metabolic syndrome: a meta-analysis study. Journal of Sexual Medicine 8 272-283. (doi:10.1111/j.1743-6109.2010.01991.x)

Corona G, Rastrelli G, Vignozzi L, Mannucci E \& Maggi M 2011 b Testosterone, cardiovascular disease and the metabolic syndrome. Best Practice \& Research. Clinical Endocrinology \& Metabolism 25 337-353. (doi:10.1016/j.beem.2010.07.002)

De Lean A, Munson PJ \& Rodbard D 1978 Simultaneous analysis of famiglie of sigmoidal curves: application to biomassa, radioligand assay, and physiological dose-response curves. American Journal of Physiology 235 97-102.

De Marzo AM, Platz EA, Sutcliffe S, Xu J, Grönberg H, Drake CG, Nakai Y, Isaacs WB \& Nelson WG 2007 Inflammation in prostate carcinogenesis. Nature Reviews. Cancer 7 256-269. (doi:10.1038/nrc2090)

Donnell RF 2011 Benign prostate hyperplasia: a review of the year's progress from bench to clinic. Current Opinion in Urology 21 22-26. (doi:10.1097/ MOU.0b013e32834100dd)

Durand RE \& Raleigh JA 1998 Identification of nonproliferating but viable hypoxic tumor cells in vivo. Cancer Research 58 3547-3550.

Fibbi B, Penna G, Morelli A, Adorini L \& Maggi M 2010 Chronic inflammation in the pathogenesis of benign prostatic hyperplasia. International Journal of Andrology 33 475-488. (doi:10.1111/j.1365-2605. 2009.00972.x)

Fijak M, Schneider E, Klug J, Bhushan S, Hackstein H \& Schuler G 2011 Testosterone replacement effectively inhibits the development of experimental autoimmune orchitis in rats: evidence for a direct role of testosterone on regulatory $\mathrm{T}$ cell expansion. Journal of Immunology $\mathbf{1 8 6}$ 5162-5172. (doi:10.4049/jimmunol.1001958)

Filippi S, Vignozzi L, Morelli A, Chavalmane AK, Sarchielli E, Fibbi B, Saad F, Sandner P, Ruggiano P, Vannelli GB et al. 2009 Testosterone partially ameliorates metabolic profile and erectile responsiveness to PDE5 inhibitors in an animal model of male metabolic syndrome. Journal of Sexual Medicine 6 3274-3288. (doi:10.1111/j.1743-6109.2009.01467.x)

Fox HS 1992 Androgen treatment prevents diabetes in nonobese diabetic mice. Journal of Experimental Medicine 175 1409-1412. (doi:10.1084/jem. 175.5.1409)

Gorbachinsky I, Akpinar H \& Assimos DG 2010 Metabolic syndrome and urologic diseases. Reviews in Urology 12 e157-e180.
Haider A, Gooren LJ, Padungtod P \& Saad F 2009 Concurrent improvement of the metabolic syndrome and lower urinary tract symptoms upon normalisation of plasma testosterone levels in hypogonadal elderly men. Andrologia 41 7-13. (doi:10.1111/j.1439-0272.2008.00880.x)

Harbuz MS, Perveen-Gill Z, Lightman SL \& Jessop DS 1995 A protective role for testosterone in adjuvant-induced arthritis. British Journal of Rheumatology 34 1117-1122. (doi:10.1093/rheumatology/34.12.1117)

Holmäng S, Mårin P, Lindstedt G \& Hedelin H 1993 Effect of long-term oral testosterone undecanoate treatment on prostate volume and serum prostatespecific antigen concentration in eugonadal middle-aged men. Prostate $\mathbf{2}$ 99-106. (doi:10.1002/pros.2990230203)

Kalinchenko S, Vishnevskiy EL, Koval AN, Mskhalaya GJ \& Saad F 2008 Beneficial effects of testosterone administration on symptoms of the lower urinary tract in men with late-onset hypogonadism: a pilot study. Aging Male 11 57-61. (doi:10.1080/13685530801953994)

Karazindiyanoğlu S \& Çayan S 2008 The effect of testosterone therapy on lower urinary tract symptoms/bladder and sexual functions in men with symptomatic late-onset hypogonadism. Aging Male 11 146-149. (doi:10. 1080/13685530802290438)

Kardassis D, Murphy C, Fotsis T, Moustakas A \& Stournaras C 2009 Control of transforming growth factor beta signal transduction by small GTPases. FEBS Journal 276 2947-2965. (doi:10.1111/j.1742-4658.2009. 07031.x)

Krajewska M, Banares S, Zhang EE, Huang X, Scadeng M, Jhala US, Feng GS \& Krajewski S 2008 Development of diabesity in mice with neuronal deletion of Shp2 tyrosine phosphatase. American Journal of Pathology 172 1312-1324. (doi:10.2353/ajpath.2008.070594)

Kristal AR, Schenk JM, Song Y, Arnold KB, Neuhouser ML, Goodman PJ, Lin DW, Stanczyk FZ \& Thompson IM 2008 Serum steroid and sex hormone-binding globulin concentrations and the risk of incident benign prostatic hyperplasia: results from the prostate cancer prevention trial. American Journal of Epidemiology 168 1416-1424. (doi:10.1093/aje/ kwn272)

Laven BA, Orsini N, Andersson SO, Johansson JE, Gerber GS \& Wolk A 2008 Birth weight, abdominal obesity and the risk of lower urinary tract symptoms in a population based study of Swedish men. Journal of Urology 179 1891-1895. (doi:10.1016/j.juro.2008.01.029)

Lédée N, Lombroso R, Lombardelli L, Selva J, Dubanchet J, Chaouat G, Frankenne F, Foidart JM, Maggi E, Romagnani S et al. 2008 Cytokines and chemokines in follicular fluids and potential of the corresponding embryo: the role of granulocyte colony-stimulating factor. Human Reproduction $\mathbf{2 3}$ 2001-2009. (doi:10.1093/humrep/den192)

Legrand D, Elass E, Carpentier M \& Mazurier J 2005 Lactoferrin: a modulator of immune and inflammatory responses. Cellular and Molecular Life Sciences 62 2549-2559. (doi:10.1007/s00018-005-5370-2)

Litman HJ, Steers WD, Wei JT, Kupelian V, Link CL, McKinlay JB \& Boston Area Community Health Survey Investigators 2007 Relationship of lifestyle and clinical factors to lower urinary tract symptoms: results from Boston area community health survey. Urology 70 916-921. (doi:10.1016/j. urology.2007.06.1117)

Liva SM \& Voskhul RR 2001 Testosterone acts directly on $\mathrm{CD}^{+}{ }^{+} \mathrm{T}$ lymphocytes to increase IL-10 production. Journal of Immunology 167 2060-2067.

Lorne E, Dupont H \& Abraham E 2010 Toll-like receptors 2 and 4: initiators of non-septic inflammation in critical care medicine? Intensive Care Medicine 36 1826-1835. (doi:10.1007/s00134-010-1983-5)

Lotti F, Corona G, Colpi GM, Filimberti E, Degli Innocenti S, Mancini M, Baldi E, Noci I, Forti G, Adorini L et al. 2011 Elevated body mass index correlates with higher seminal plasma interleukin 8 levels and ultrasonographic abnormalities of the prostate in men attending an andrology clinic for infertility. Journal of Endocrinological Investigation (In press).

Martin SA, Haren MT, Marshall VR, Lange K, Wittert GA \& Members of the Florey Adelaide Male Ageing Study 2011 Prevalence and factors associated with uncomplicated storage and voiding lower urinary tract symptoms in community-dwelling Australian men. World Journal of Urology 29 179-184. (doi:10.1007/s00345-010-0605-8) 
Michel MC, Mehlburger L, Schumacher H, Bressel HU \& Goepel M 2000 Effect of diabetes on lower urinary tract symptoms in patients with benign prostatic hyperplasia. Journal of Urology 163 1725-1729. (doi:10.1016/ S0022-5347(05)67529-5)

Michel MC, Heemann U, Schumacher H, Mehlburger L \& Goepel M 2004 Association of hypertension with symptoms of benign prostatic hyperplasia. Journal of Urology 172 1390-1393. (doi:10.1097/01.ju.0000139995. 85780.d8)

Miwa Y, Kaneda T \& Yokoyama O 2008 Association between lower urinary tract symptoms and serum levels of sex hormones in men. Urology $\mathbf{7 2}$ 552-555. (doi:10.1016/j.urology.2008.04.023)

Mongiu AK \& McVary KT 2009 Lower urinary tract symptoms, benign prostatic hyperplasia, and obesity. Current Urology Reports 10 247-253. (doi:10.1007/s11934-009-0041-8)

Morelli A, Filippi S, Comeglio P, Sarchielli E, Chavalmane AK, Vignozzi L, Fibbi B, Silvestrini E, Sandner P, Gacci M et al. 2010a Acute vardenafil administration improves bladder oxygenation in spontaneously hypertensive rats. Journal of Sexual Medicine 7 107-120. (doi:10.1111/j.1743-6109. 2009.01558.x)

Morelli A, Vignozzi L, Maggi M \& Adorini L 2011 Farnesoid X receptor activation improves erectile dysfunction in models of metabolic syndrome and diabetes. Biochimica et Biophysica Acta 1812 859-866.

Moul S \& McVary KT 2010 Lower urinary tract symptoms, obesity and the metabolic syndrome. Current Opinion in Urology 20 7-12. (doi:10.1097/ MOU.0b013e3283336f3f)

Nickel JC 1994 Prostatic inflammation in benign prostatic hyperplasia-the third component? Canadian Journal of Urology 1 1-4.

Parsons JK 2011 Lifestyle factors, benign prostatic hyperplasia, and lower urinary tract symptoms. Current Opinion in Urology 21 1-4. (doi:10.1097/ MOU.0b013e32834100c9)

Penna G, Fibbi B, Amuchastegui S, Corsiero E, Laverny G, Silvestrini E, Chavalmane A, Morelli A, Sarchielli E, Vannelli GB et al. 2009 The vitamin D receptor agonist elocalcitol inhibits IL-8-dependent benign prostatic hyperplasia stromal cell proliferation and inflammatory response by targeting the RhoA/Rho kinase and NF-kappaB pathways. Prostate 69 480-493. (doi:10.1002/pros.20896)

Pradidarcheep W 2008 Lower urinary tract symptoms and its potential relation with late-onset hypogonadism. Aging Male 11 51-55. (doi:10. 1080/13685530801954026)

Quintar AA, Roth FD, De Paul AL, Aoki A \& Maldonado CA 2006 Toll-like receptor 4 in rat prostate: modulation by testosterone and acute bacterial infection in epithelial and stromal cells. Biology of Reproduction 75 664-672. (doi:10.1095/biolreprod.106.053967)

Roberts RO, Jacobson DJ, Rhodes T, Klee GG, Leiber MM \& Jacobsen SJ 2004 Serum sex hormones and measures of benign prostatic hyperplasia. Prostate 61 124-131. (doi:10.1002/pros.20080)

Robinette CL 1988 Sex-hormone-induced inflammation and fibromuscular proliferation in the rat lateral prostate. Prostate 12 271-286. (doi:10.1002/ pros.2990120310)

Rohrmann S, Smit E, Giovannucci E \& Platz EA 2004 Associations of obesity with lower urinary tract symptoms and noncancer prostate surgery in the Third National Health and Nutrition Examination Survey. American Journal of Epidemiology 159 390-397. (doi:10.1093/aje/kwh060)

Saad F, Gooren L, Haider A \& Yassin A 2007 An exploratory study of the effects of 12 month administration of the novel long-acting testosterone undecanoate on measures of sexual function and the metabolic syndrome. Archives of Andrology 53 353-357. (doi:10.1080/01485010701730880)

Saad F, Gooren LJ, Haider A \& Yassin A 2008 A dose-response study of testosterone on sexual dysfunction and features of the metabolic syndrome using testosterone gel and parenteral testosterone undecanoate. Journal of Andrology 29 102-105. (doi:10.2164/jandrol.107.002774)

Schatzl G, Brössner C, Schmid S, Kugler W, Roehrich M, Treu T, Szalay A, Djavan B, Schmidbauer CP, Söregi S et al. 2000 Endocrine status in elderly men with lower urinary tract symptoms: correlation of age, hormonal status, and lower urinary tract function. The Prostate Study Group of the Austrian Society of Urology. Urology 55 397-402. (doi:10.1016/S00904295(99)00473-2)
Seim A, Hoyo C, Ostbye T \& Vatten L 2005 The prevalence and correlates of urinary tract symptoms in Norwegian men: the HUNT study. British Journal of Urology International 96 88-92. (doi:10.1111/j.1464-410X.2005. 05573.x)

Sfanos KS, Wilson BA, De Marzo AM \& Isaacs WB 2009 Acute inflammatory proteins constitute the organic matrix of prostatic corpora amylacea and calculi in men with prostate cancer. PNAS 106 3443-3448. (doi:10.1073/ pnas.0810473106)

Shigehara K, Sugimoto K, Konaka H, Iijima M, Fukushima M, Maeda Y, Mizokami A, Koh E, Origasa H, Iwamoto T et al. 2011 Androgen replacement therapy contributes to improving lower urinary tract symptoms in patients with hypogonadism and benign prostate hypertrophy: a randomised controlled study. Aging Male 14 53-58. (doi:10.3109/ 13685538.2010.518178)

Sims GP, Rowe DC, Rietdijk ST, Herbst R \& Coyle AJ 2010 HMGB1 and RAGE in inflammation and cancer. Annual Review of Immunology 28 367-388. (doi:10.1146/annurev.immunol.021908.132603)

St Sauver JL, Jacobson DJ, McGree ME, Girman CJ, Klee GG, Lieber MM \& Jacobsen SJ 2011 Associations between longitudinal changes in serum estrogen, testosterone, and bioavailable testosterone and changes in benign urologic outcomes. American Journal of Epidemiology 173 787-796. (doi:10. 1093/aje/kwq438)

Tan AH, Gilling PJ, Kennett KM, Fletcher H \& Fraundorfer MR 2003 Longterm results of high-power holmium laser vaporization (ablation) of the prostate. British Journal of Urology International 92 707-709. (doi:10.1046/j. 1464-410X.2003.04474.x)

Tangbanluekal L \& Robinette CL 1993 Prolactin mediates estradiol-induced inflammation in the lateral prostate of Wistar rats. Endocrinology 132 2407-2416. (doi:10.1210/en.132.6.2407)

Tomita K, Mizoue T \& Matsumoto T 2009 Lower urinary tract symptoms in relation to lifestyle and medical conditions in Japanese workers. International Journal of Urology 16 493-498. (doi:10.1111/j.1442-2042.2009.02276.x)

Traish AM, Miner MM, Morgentaler A \& Zitzmann M 2011 Testosterone deficiency. American Journal of Medicine 124 578-587. (doi:10.1016/j. amjmed.2010.12.027)

Trifiro MD, Parsons JK, Palazzi-Churas K, Bergstrom J, Lakin C \& BarrettConnor E 2010 Serum sex hormones and the 20-year risk of lower urinary tract symptoms in community-dwelling older men. British Journal of Urology International 105 1554-1559. (doi:10.1111/j.1464-410X.2009.09090.x)

Via LE, Lin PL, Ray SM, Carrillo J, Allen SS, Eum SY, Taylor K, Klein E, Manjunatha U, Gonzales J et al. 2008 Tuberculous granulomas are hypoxic in guinea pigs, rabbits, and nonhuman primates. Infection and Immunity $\mathbf{7 6}$ 2333-2340. (doi:10.1128/IAI.01515-07)

Vignozzi L, Filippi S, Morelli A, Ambrosini S, Luconi M, Vannelli GB, Donati S, Crescioli C, Zhang XH, Mirone V et al. 2006 Effect of chronic tadalafil administration on penile hypoxia induced by cavernous neurotomy in the rat. Journal of Sexual Medicine 3 419-431. (doi:10.1111/j.1743-6109.2006. 00208.x)

Vignozzi L, Morelli A, Filippi S, Vannelli GB, Mungai S, Marini M, Boddi V, Forti G \& Maggi M 2008 Effect of sildenafil administration on penile hypoxia induced by cavernous neurotomy in the rat. International Journal of Impotence Research 20 60-67. (doi:10.1038/sj.ijir.3901596)

Vignozzi L, Filippi S, Morelli A, Marini M, Chavalmane A, Fibbi B, Silvestrini E, Mancina R, Carini M, Vannelli GB et al. 2009 Cavernous neurotomy in the rat is associated with the onset of an overt condition of hypogonadism. Journal of Sexual Medicine 6 1270-1283. (doi:10.1111/j. 1743-6109.2008.01208.x)

Vignozzi L, Morelli A, Filippi S, Comeglio P, Chavalmane AK, Marchetta M, Toce M, Yehiely-Cohen R, Vannelli GB, Adorini L et al. 2011 Farnesoid X receptor activation improves erectile function in animal models of metabolic syndrome and diabetes. Journal of Sexual Medicine 8 57-77. (doi:10.1111/j.1743-6109.2010.02073.x)

Wang ZH, Zhang W, Gong HP, Guo ZX, Zhao J, Shang YY, Feng JB, Zhang Y \& Zhong M 2010 Expression of STAMP2 in monocytes associates with cardiovascular alterations. European Journal of Clinical Investigation $\mathbf{4 0}$ 490-496. (doi:10.1111/j.1365-2362.2010.02288.x)

Yanamandra K, Alexeyev O, Zamotin V, Srivastava V, Shchukarev A, Brorsson AC, Tartaglia GG, Vogl T, Kayed R, Wingsle G et al. 2009 
Amyloid formation by the pro-inflammatory S100A8/A9 proteins in the ageing prostate. PLoS ONE 4 e5562-e5576. (doi:10.1371/journal.pone. 0005562)

Yatkin E, Bernoulli J, Talvitie EM \& Santti R 2009 Inflammation and epithelial alterations in rat prostate: impact of the androgen to oestrogen ratio. International Journal of Andrology 32 399-410. (doi:10.1111/j.13652605.2008.00930.x)

Zhu J, Yamane H \& Paul WE 2010 Differentiation of effector CD4 T cell populations. Annual Review of Immunology 28 445-489. (doi:10.1146/ annurev-immunol-030409-101212)
Zitzmann M 2009 Testosterone deficiency, insulin resistance and the metabolic syndrome. Nature Reviews. Endocrinology 5 673-681. (doi:10. 1038/nrendo.2009.212)

Received in final form 7 October 2011

Accepted 18 October 2011

Made available online as an Accepted Preprint 18 October 2011 